Article

\title{
Ecodesign Strategy for Demand-Oriented Electrical and Electronic Products
}

\author{
Yongguang Zhong ${ }^{1}$ and Qian Wang ${ }^{2, *}$ (D) \\ 1 Business School, Qingdao University, Qingdao 266071, China; zhongyongguang@qdu.edu.cn \\ 2 School of Transportation Management, Nanjing Vocational Institute of Transport Technology, \\ Nanjing 211188, China \\ * Correspondence: wangqian2015@njitt.edu.cn
}

Citation: Zhong, Y.; Wang, Q

Ecodesign Strategy for

Demand-Oriented Electrical and

Electronic Products. Sustainability

2022, 14, 24. https://doi.org/

$10.3390 /$ su14010024

Academic Editors: Atour Taghipour, Malek Masmoudi and

Idiano D'Adamo

Received: 31 October 2021

Accepted: 16 December 2021

Published: 21 December 2021

Publisher's Note: MDPI stays neutral with regard to jurisdictional claims in published maps and institutional affiliations.

Copyright: (c) 2021 by the authors Licensee MDPI, Basel, Switzerland. This article is an open access article distributed under the terms and conditions of the Creative Commons Attribution (CC BY) license (https:// creativecommons.org/licenses/by/ $4.0 /)$.

\begin{abstract}
Governments of various countries have formulated relevant EPR environmental regulations for environmental pollution caused by electrical and electronic products, and enterprises mainly respond to this regulation through product ecodesign strategies. In view of this, this paper takes a three-stage supply chain system composed of a manufacturer, a retailer and a third-party recycler as the research object, and develops a demand-oriented product ecodesign strategy for five scenarios under different environmental regulations, including eco-input subsidy, sales subsidy, consumption subsidy and recycling subsidy. This study finds that the manufacturer does not actively engage in product ecodesign if the government does not implement subsidy policies; when the government implements subsidy policies such as eco-input subsidy, sales subsidy, or consumption subsidy, the manufacturer will design a high-level ecological product. However, under the recycling subsidy policy, the manufacturer will design a low-level ecological product. These results suggest that different subsidy policies may lead to different eco-product strategies of the manufacturer. In particular, the recycling subsidy policy can encourage a recycler to recycle actively, thus reducing the environmental pollution cost of a manufacturer, but the manufacturer is reluctant to improve the ecological level of the finished product.
\end{abstract}

Keywords: electrical and electronic products; supply chain; ecodesign; recycling regulation; subsidy policy

\section{Introduction}

With the continuous improvement of people's living standards, electrical and electronic products are increasingly widely used. They bring convenience to peoples' lives, but at the same time, the disposal of waste electrical and electronic products has become a problem. In addition to the waste resources caused by the imperfect treatment process, what is more serious is the lack of environmental protection facilities during the treatment of the waste products, which generates waste gas and water that cause irreversible damage to the environment. In order to regulate the recycling of waste products, promote the comprehensive utilization of resources, and protect the environment and human health, the government has introduced a series of laws and regulations to regulate the industry. From the point of view of the regulations that have been enacted on waste product recycling, the mechanisms of the government's role in producers' recycling activities can be focused on the following categories: recycling legislation, extended producer responsibility (EPR), and the incentive and penalty of government. In practice, the government often uses a combination of regulations to achieve the goal of product recovery [1]. In view of the EPR, environmental laws and regulations formulated by governments of various countries due to environmental pollution caused by electrical and electronic products, enterprises mainly adopt ecological design strategies to deal with them. However, the current ecological design of electrical and electronic product manufacturing enterprises mainly focuses on the ecological impact of the product itself, rather than considering how users use the product, 
which may lead to the "Jevons paradox", thus canceling the environmental protection effect of the product itself. In addition, many products are disposed of not because of the end of their "physical life" but because of the end of their "psychological life," and when that happens, it does not matter how environmentally friendly the product is. In the context of ecological consumption, these problems are prominent, thus there is a need to increase the consideration of user behavior in ecological design, and realize the organic unity of the product's environmental performance and the user's environmental behavior.

Currently, as the public is increasingly concerned about the impact of their daily activities on the environment, and many consumers are willing to pay a premium for their environmental awareness [2], thus, in electrical and electronic products, demand-oriented product ecological design has become an important measure to promote the development of ecological consumption. More environmentally friendly consumption patterns can be established by implementing demand-oriented product ecological design strategies [3,4]. To cater to customer demand and improve product competitiveness, more and more electrical and electronic product manufacturers choose to implement demand-oriented product ecological design strategies [5,6]. As an important channel for ecological information transmission between manufacturers and consumers, consumers can also learn about the environmental efforts of manufacturers through ecological products, and encourage consumers to reduce environmental damage by changing their purchase choices [7].

To this end, the main objective of this paper is to develop a demand-oriented ecodesign strategy for electrical and electronic products under government recycling regulations, and to investigate how recycling regulations and different subsidy policies affect product ecodesign, and what strategies manufacturers should use to cope with them. Based on this, this paper will further develop a product ecodesign strategy based on a combination of subsidy policies under government recycling regulations, so as to develop a reference solution for electrical and electronic products in terms of EPR regulations, production, recycling, and disposal.

This paper examines how manufacturers implement demand-oriented ecodesign in a supply chain, and how government formulates regulatory policies. Therefore, this paper focuses on two streams of literature: environmental regulations on recycling and ecodesign in a supply chain.

According to the regulations on waste product recycling promulgated by various countries and existing academic studies, the key mechanisms of government can be divided into the following categories: recycling legislation [8-10], extended producer responsibility (EPR) [11-13] and government reward and punishment mechanisms [14,15]. First of all, in terms of research on recycling legislation, some scholars find that recycling legislation can promote enterprises to improve product recycling efforts [16-18], but some scholars believe that this legislation may also hinder enterprises' efforts in carbon emission reduction $[19,20]$. Many scholars have considered the role of EPR systems for product recovery. EPR is an environmental policy approach, by which a producer's responsibility for a product is extended to the post-consumer stage of a product's life cycle including its final disposal [21-24]. This approach limits the recovery liability to upstream manufacturers, forcing them to take environmental considerations into account in product design [23,25-27]. Reference [28] studied the issue of responsibility sharing policies (RSP) in supply chains, and concluded that EPR design and RSP should be carried out simultaneously. Similarly, a generic framework for EPR design is proposed that that also models the different types of environmental regulations being implemented around the world [29]. Recently, a new framework was tested using data from the state of Washington's EPR program to represent e-waste collection, transportation, processing and disposal [30]. This study shows that EPR regulations have achieved increased recycling rates for e-waste, but the associated costs and impacts on the collection, transportation, recycling, and disposal may outweigh its benefits.

Regarding government incentives and penalties, how to guide enterprises to carry out better recycling and remanufacturing activities is the main direction to be explored by theoretical and practical circles, and incentives and penalties are an effective measure. 
There are several types of incentives and penalties already being practiced by governments, such as carbon/emission tax [31,32], cap-and-trade [33-35] and subsidy [36,37]. In the actual operation process, the government often adopts not only a single regulation, but a combination of various regulations in order to achieve the goal of product recycling. Many scholars have discussed the benefit of the reward-penalty mechanism in a two-period, closed-loop supply chain, where a manufacturer sells new products in the first period, and then commits the collector to collect used products and conducts remanufacturing in the second period [38-41].

Product ecodesign is the second topic that is covered in this paper. The practice of product ecodesign aims to reduce substances of environmental concern [42], obtaining more demand and influencing production costs [43-45]. Since the concept of ecodesign was put forward, government departments, industry and academia have paid great attention to ecological design. From different dimensions and perspectives, ecological design has been studied extensively, and different understandings of the connotation of ecological design have been formed. The early stages of product design, such as the planning and concept design stages, have a great impact on the ecological effects of the product. Therefore, it is crucial to consider environmental factors in the early stages of product design. Systematically integrating quality, cost and environment at the early stages of design have proved to be an innovative approach to product ecological design [46-48]. Recently, there have also been many studies on the packaging and labeling of products in ecodesign [49-52]. In addition, because the lifecycle-based product and process parameters are related to design and development stages $[53,54]$, life-cycles can lead to different conclusions about the way a product is ecodesigned during ecodesign evaluation [55,56], and thus lifecycles have been widely used and studied as a common tool for product ecodesign strategy evaluation [57-59].

Considering the above, the implementation of product ecodesign can make the manufacturers of electrical and electronic products, in the product design stage, consider environmental protection, so as to better fulfill the responsibility of product recycling, utilization and final disposal, to achieve maximum economic, environmental and social benefits. However, although the academic research on product remanufacturing has been widely discussed, there is an obvious lack of research on product ecodesign, especially from the perspective of supply chain system and whole lifecycle, using operation optimization and game theory to study the ecodesign strategy under government recycling regulations.

The remainder of this paper is structured as follows: Section 2 presents the problem description and model assumptions; Section 3 is the model construction and solution, which is the core research content of this paper; Section 4 focuses on the comparative analysis of the optimal decisions and profits of supply chain members under various scenarios; Section 5 uses numerical examples to verify the relevant conclusions in the model analysis and comparative analysis, and further investigates the relevant problems that cannot be analyzed comparatively due to the complexity of the model. Section 6 provides the conclusion. All proofs of this paper are in the Appendix A.

\section{Model Development}

Considering a supply chain system consisting of a manufacturer, a retailer, and a thirdparty recycler, where the supply chain members are risk-neutral and seek to maximize their profit, this paper uses a Stackelberg game theory, in which the manufacturer is the leader and produces electrical and electronic products, the retailer and the third-party recycler, are the followers. The retailer is responsible for selling the products, and the third-party recycler is commissioned by the manufacturer to recycle the waste products. In response to the environmental pollution caused by e-waste, the government implements punitive recycling regulations to force the manufacturer to fulfill the EPR. Under the recycling regulation, the manufacturer will carry out ecodesign of products, considering that the ecodesign not only reduces the environmental impact of the e-waste generated, but also the ecological products can increase consumer utility and thus influence demand, such as the 
design of products in terms of energy saving and appearance. At the same time, in order to incentivize the manufacturer to improve the eco-level of the ecodesign, the government will likely use subsidy policies such as eco-input subsidy, sales subsidy, consumption subsidy, and recycling subsidy.

The decision sequence is as follows: first, the manufacturer undertakes the ecodesign of the product based on the recycling regulation and subsidy policy provided by the government, and decides the eco-level of the products, $e$, and then decides the wholesale price, $w$, for reselling the products to the retailer; at the same time, under the EPR, the manufacturer commissions the third-party recycler to recycle the used electronic eco-products and decides the recycling transfer price, $\mu$; then, the retailer uses the manufacturer's eco-level of product and wholesale price to decide the sales price $p$, and under the sales subsidy policy and the consumption subsidy policy, the amount of subsidy by government will also be considered; finally, the third-party recycler relies on the manufacturer's eco-level of product and the recycling transfer price to decide the collected price $\tau$, and when the government implements the recycling subsidy, the recycling subsidy will also be relied on.

According to references [1], the relevant assumptions and functional forms of this paper are as follows:

Hypothesis 1 (H1). The manufacturer undertakes the ecodesign for demand and the environment. The eco-product will increase consumer utility by $\eta e$, and the environmental pollution cost of the unrecycled eco-product is $\varepsilon-\delta e$. Where $\eta$ is the effect of ecodesign on consumer utility; $\varepsilon$ is the environmental pollution cost per unit of unrecycled waste nonecological products, and $\delta$ is the impact of product ecodesign on the environmental pollution cost caused by unrecycled waste ecological products.

Hypothesis $2 \mathbf{( H 2 )}$. The government imposes recycling regulations related to eco-level. The government imposes a unit penalty of $k-\delta$ e for discarded eco-products that are not recycled and $\eta$ for discarded nonecological products. Here it is assumed that the government will transfer all the unit costs of environmental pollution reduction by ecodesign to the manufacturer in the form of recycling regulations.

Hypothesis 3 (H3). The manufacturer's product eco-input cost is $C(e)=\theta e^{2}$, where $\theta$ is the cost efficiency of the manufacturer's product ecodesign input, and the smaller its value, the more efficient the input.

Hypothesis $4 \mathbf{( H 4 ) . ~ C o n s u m e r s ~ v a l u e ~ t h e ~ p r o d u c t s ~ p r o d u c e d ~ b y ~ t h e ~ m a n u f a c t u r e r ~ a s ~} v$. Considering that consumers are heterogeneous, it is assumed that $v$ is uniformly distributed obeying $[0,1]$, which leads to: under the demand-oriented ecodesign strategy, the sales volume of products without consumption subsidy policy is $q=1-p+\eta e$, and the sales volume of products under consumption subsidy is $q=1-p+\eta e+b$, where $b$ is the amount of consumption subsidy given by the government to a certain consumer who buys eco-products; the consumer surplus is $C S=\frac{q^{2}}{2}$; it is further assumed that consumers' price sensitivity to the waste products is homogeneous and both are $\lambda$. Without considering consumers' environmental preferences, it is assumed that the volume of product recycling is $R=\lambda \tau$.

Hypothesis 5 (H5). To reduce the impact on environmental pollution, the designed eco-products will not cause further environmental pollution after recycling when they are disposed of and have no recycling value. Also, it is assumed that the cost of recycling discarded eco-products by the third-party recycler has no cost other than the recycling price paid to consumers.

In addition, the subscripts $i \in\{m, r, t\}$ represent the manufacturer, the retailer, and the third-party recycler, respectively; the superscripts $j \in\{D N, D E, D S, D B, D F\}$ denote the government subsidy policy scenarios of no subsidy, eco-input subsidy, sales subsidy, consumption subsidy, and recycling subsidy under the demand-oriented product ecodesign 
strategy, respectively, where: the percentage of eco-input subsidy is $\alpha$, the unit sales subsidy is $s$, the unit consumption subsidy is $b$, and the unit recovery subsidy is $f$; The superscript " **" represents the optimal solution or the optimal profit. The specific model parameters and descriptions in this chapter are shown in Table 1.

Table 1. Summary of basic notations.

\begin{tabular}{|c|c|}
\hline \multicolumn{2}{|c|}{ Parameters } \\
\hline$c$ & Manufacturer's unit production cost, independent of product ecodesign; \\
\hline$\theta$ & $\begin{array}{l}\text { The cost efficiency of the manufacturer's product ecodesign inputs, the smaller the } \\
\text { value, the more effective the ecodesign; }\end{array}$ \\
\hline$\eta$ & The impact of product ecodesign on consumer utility; \\
\hline$k$ & $\begin{array}{l}\text { Government penalties for units of nonrecycled, nonecological products under } \\
\text { environmental regulation; }\end{array}$ \\
\hline$\varepsilon$ & $\begin{array}{l}\text { Unit cost of pollution to the environment from the waste nonecological } \\
\text { products unrecovered; }\end{array}$ \\
\hline$\delta$ & $\begin{array}{l}\text { The impact of product ecodesign on the cost of environmental pollution caused by } \\
\text { unrecovered and discarded eco-products }\end{array}$ \\
\hline$\lambda$ & The sensitivity of recycling price; \\
\hline$\alpha$ & $\begin{array}{l}\text { Percentage of government subsidies to incentivize manufacturers' input costs for } \\
\text { product ecodesign; }\end{array}$ \\
\hline$s$ & Unit subsidy for government incentives for the retailer to sell eco-products; \\
\hline$b$ & Unit subsidy for government incentives for consumers to purchase eco-products; \\
\hline$f$ & $\begin{array}{l}\text { Unit subsidy for government incentives for the third-party recycler to collect the } \\
\text { waste eco-products. }\end{array}$ \\
\hline \multicolumn{2}{|c|}{ Decision variables } \\
\hline$w$ & Unit wholesale prices charged by the manufacturer to retailer; \\
\hline$p$ & The sales price of the eco-products; \\
\hline$\mu$ & The transfer price paid by the manufacturer to the third-party recycler; \\
\hline$\tau$ & The recycling price of the waste eco-products; \\
\hline$e$ & The level of ecodesign. \\
\hline \multicolumn{2}{|c|}{ Dependent variables } \\
\hline$q$ & Demand for eco-products; \\
\hline$R$ & Number of waste eco-products recycled; \\
\hline$\pi_{i}^{j}$ & $\begin{array}{l}\text { Profit of supply chain member } i \text { in case } j \text {, where } i \in\{m, r, t\} \text { and } \\
j \in\{D N, D E, D S, D B, D F\}\end{array}$ \\
\hline$\pi_{g}^{j}$ & Social welfare of the government under scenario $j$. \\
\hline
\end{tabular}

\section{Scenarios}

\subsection{No Subsidy Policy}

Under the government's penalty recycling regulation, the manufacturer's profit function is as follows:

$$
\pi_{m}^{D N}=(w-c) q-\theta e^{2}-\mu R-(k-\delta e)(q-R)
$$

In Equation (1), the last term on the right-hand side of the equation is the penalty cost for waste eco-products unrecovered.

The profit functions for the retailer and third-party recycler, respectively, can be presented as follows:

$$
\begin{aligned}
& \pi_{r}^{D N}=(p-w) q, \\
& \pi_{t}^{D N}=(\mu-\tau) R .
\end{aligned}
$$


From the above profit function of each decision maker in the supply chain, combined with consumer surplus and environmental pollution caused by the unrecovered waste, the government will aim to maximize social welfare with the following social welfare function:

$$
\pi_{g}^{D N}=\pi_{m}^{D N}+\pi_{r}^{D N}+\pi_{t}^{D N}+\frac{q^{2}}{2}-(\varepsilon-k)(q-R) .
$$

In Equation (4), the sum of the first three terms on the right-hand side of the equation is the supply chain profit, the fourth term is the consumer surplus, and the last term is the actual cost of environmental pollution from the unrecovered waste borne by the government under the recycling regulation.

Lemma 1. The manufacturer's profit maximization condition regarding the level of ecodesign is $\theta>\theta^{D N}=\frac{(\eta+\delta)^{2}+\lambda \delta^{2}}{8}$.

It follows that the manufacturer's optimal product ecological level when $\theta>\theta^{D N}$ :

$$
e^{D N *}=\frac{(1-c-k)(\eta+\delta)-\lambda \delta k}{8 \theta-(\eta+\delta)^{2}-\lambda \delta^{2}},
$$

Combining the above, the optimal pricing decisions of the supply chain members under the no subsidy policy can be obtained as follows.

$$
\begin{gathered}
w^{D N *}=\frac{(8(1+k+c) \theta-2(\eta+\delta)(c \eta+\eta k+\delta)-\lambda \delta(c \delta-k \eta+\delta))}{2\left(8 \theta-(\eta+\delta)^{2}-\lambda \delta^{2}\right)}, \\
\mu^{D N *}=\frac{8 k \theta-(\eta+\delta)(\delta-c \delta+k \eta)}{2\left(8 \theta-(\eta+\delta)^{2}-\lambda \delta^{2}\right)}, \\
p^{D N *}=\frac{(8(3+k+c) \theta-4(\eta+\delta)(c \eta+\eta k+\delta)-\lambda \delta(c \delta+3 \eta k+3 \delta))}{4\left(8 \theta-(\eta+\delta)^{2}-\lambda \delta^{2}\right)}, \\
\tau^{D N *}=\frac{8 k \theta-(\eta+\delta)(\delta-c \delta+\eta k)}{4\left(8 \theta-(\eta+\delta)^{2}-\lambda \delta^{2}\right)} .
\end{gathered}
$$

Further, the optimal profit for the manufacturer, retailer and the third-party recycler can be obtained as:

$$
\begin{gathered}
\pi_{m}^{D N *}=\frac{8\left((1-c-k)^{2}+\lambda k^{2}\right) \theta-\lambda(\delta-c \delta+k \eta)^{2}}{8\left(8 \theta-(\eta+\delta)^{2}-\lambda \delta^{2}\right)}, \\
\pi_{r}^{D N *}=\frac{(8(1-k-c) \theta-\lambda \delta(\delta-c \delta+k \eta))^{2}}{16\left(8 \theta-(\eta+\delta)^{2}-\lambda \delta^{2}\right)^{2}}, \\
\pi_{t}^{D N *}=\frac{(8 k \theta-(\eta+\delta)(\delta-c \delta+k \eta))^{2} \lambda}{16\left(8 \theta-(\eta+\delta)^{2}-\lambda \delta^{2}\right)^{2}} .
\end{gathered}
$$

The impact of government recycling regulation on the decision and profit of supply chain members can be studied by conducting sensitivity analysis of the optimal decision and profit of each supply chain subject with respect to $k$, as shown in Proposition 1 and Proposition 2 below:

Proposition 1. $\frac{d e^{D N *}}{d k}<0, \frac{d w^{D N *}}{d k}>0, \frac{d \mu^{D N *}}{d k}>0, \frac{d p^{D N *}}{d k}>0$ and $\frac{d \tau^{D N *}}{d k}>0$.

Proposition 1 illustrates that as the penalty of recycling regulation increases, the level of ecodesign will subsequently decrease, the manufacturer's wholesale price and recycling 
transfer price will increase. At the same time, the retailer's sales price and recycling price to the third-party recycler will increase, implying that stronger regulation will reduce the manufacturer's incentive to design demand-oriented eco-products, but will increase the wholesale price and the sales prices, which would also stimulate the manufacturer to increase transfer price to the third-party recycler, which in turn would indirectly incentivize the recycler to increase recycling price.

Proposition 2. $\frac{d \pi_{m}^{D N *}}{d k}<0, \frac{d \pi_{r}^{D N *}}{d k}<0$ and $\frac{d \pi_{t}^{D N *}}{d k}>0$.

Proposition 2 illustrates that as government recycling regulation become more punitive, the profits of both the manufacturer and the retailer will decrease, but the profits of the third-party recycler will increase. Proposition 2 implies that under a demand-oriented product ecodesign strategy, the government imposes punitive recycling regulation to the detriment of the manufacturer and the retailer, and only to the benefit of the third-party recycler who is responsible for recycling the waste eco-products. This means that the manufacturer will not be motivated to invest in demand-oriented product ecodesign activities if punitive recycling regulations are not related to the level of product ecodesign. Therefore, under the policy of no government subsidy, the government needs to change the existing traditional recycling regulation, so this paper chooses the recycling regulation related to the ecological level. In extreme cases, if the impact of ecodesign on the environmental cost of unrecycled waste products is large enough to offset the cost of environmental penalties, this makes it profitable for the manufacturer to implement the product ecodesign, thus providing the theoretical and practical support for this paper.

\subsection{Eco-Input Subsidy Policy}

Under the government's implementation of punitive recycling regulation, in order to incentivize the manufacturer to design the products ecologically, the government will subsidize the manufacturer's product eco-input costs proportionally, which results in the following profit function for the manufacturer:

$$
\pi_{m}^{D E}=(w-c) q-(1-\alpha) \theta e^{2}-\mu R-(k-\delta e)(q-R),
$$

In Equation (13), the second term on the right-hand side of the equation is the ecoinput cost of the product borne by the manufacturer under the government's eco-input subsidy. Since the government eco-input subsidy does not affect the form of profit functions for the retailer and the third-party recycler, they are as follows:

$$
\begin{aligned}
& \pi_{r}^{D E}=(p-w) q, \\
& \pi_{t}^{D E}=(\mu-\tau) R .
\end{aligned}
$$

From the above profit function of each decision maker in the supply chain, combined with consumer surplus and environmental pollution caused by the unrecycled waste, and considering government subsidy for eco-inputs to the manufacturer, the social welfare function of the government at this time is as follows:

$$
\pi_{g}^{D E}=\pi_{m}^{D E}+\pi_{r}^{D E}+\pi_{t}^{D E}+\frac{q^{2}}{2}-(\varepsilon-k)(q-R)-\alpha \theta e^{2},
$$

In Equation (16), the last term on the right-hand side of the equation is the government subsidy to the manufacturer's eco-inputs.

Lemma 2. The manufacturer's profit maximization condition regarding the level of ecodesign is $\theta>\theta^{D E}=\frac{(\eta+\delta)^{2}+\lambda \delta^{2}}{8(1-\alpha)}$. 
This leads to the following optimal product ecodesign level for the manufacturer at that time:

$$
e^{D E *}=\frac{(1-c-k)(\eta+\delta)-\lambda \delta k}{8(1-\alpha) \theta-(\eta+\delta)^{2}-\lambda \delta^{2}},
$$

Taken together, the optimal pricing decisions of each supply chain member under the government eco-input subsidy policy can be obtained as:

$$
\begin{gathered}
w^{D E *}=\frac{(8(1-\alpha)(1+k+c) \theta-2(\eta+\delta)(c \eta+\eta k+\delta)-\lambda \delta(c \delta+k \eta+\delta))}{2\left(8 \theta(1-\alpha)-(\eta+\delta)^{2}-\lambda \delta^{2}\right)}, \\
\mu^{D E *}=\frac{8(1-\alpha) k \theta-(\eta+\delta)(\delta-c \delta+k \eta)}{2\left(8(1-\alpha) \theta-(\eta+\delta)^{2}-\lambda \delta^{2}\right)}, \\
p^{D E *}=\frac{(8(1-\alpha)(3+k+c) \theta-4(\eta+\delta)(c \eta+\eta k+\delta)-\lambda \delta(c \delta+3 \eta k+3 \delta))}{4\left(8(1-\alpha) \theta-(\eta+\delta)^{2}-\lambda \delta^{2}\right)}, \\
\tau^{D E *}=\frac{8(1-\alpha) k \theta-(\eta+\delta)(\delta-c \delta+\eta k)}{4\left(8(1-\alpha) \theta-(\eta+\delta)^{2}-\lambda \delta^{2}\right)} .
\end{gathered}
$$

Further, the optimal profits for the manufacturer, the retailer and the third-party recycler under government eco-input subsidy policy can be obtained as:

$$
\begin{gathered}
\pi_{m}^{D E *}=\frac{8(1-\alpha)\left((1-k-c)^{2}+\lambda k^{2}\right) \theta-\lambda(\delta-c \delta+k \eta)^{2}}{8\left(8(1-\alpha) \theta-(\eta+\delta)^{2}-\lambda \delta^{2}\right)}, \\
\pi_{r}^{D E *}=\frac{(8(1-\alpha)(1-k-c) \theta-\lambda \delta(\delta-c \delta+k \eta))^{2}}{16\left(8(1-\alpha) \theta-(\eta+\delta)^{2}-\lambda \delta^{2}\right)^{2}}, \\
\pi_{t}^{D E *}=\frac{(8(1-\alpha) k \theta-(\eta+\delta)(\delta-c \delta+k \eta))^{2} \lambda}{16\left(8(1-\alpha) \theta-(\eta+\delta)^{2}-\lambda \delta^{2}\right)^{2}} .
\end{gathered}
$$

By conducting a sensitivity analysis of the optimal decision and profit of each supply chain member regarding the percentage of government eco-input subsidy $\alpha$, the impact of government eco-input subsidy policy on the decision and profit of supply chain members can be studied, as shown in Proposition 3 and Proposition 4.

\section{Proposition 3.}

(i) $\frac{d e^{D E *}}{d \alpha}>0, \frac{d \mu^{D E *}}{d \alpha}<0$ and $\frac{d \tau^{D E *}}{d \alpha}<0$;

(ii) $\eta \geq \delta$, then $\frac{d w^{D E *}}{d \alpha} \geq 0$, otherwise $\frac{d w^{D E *}}{d \alpha}<0$;

(iii) $\eta \geq \frac{\delta}{3}$, then $\frac{d p^{D E *}}{d \alpha} \geq 0$, otherwise $\frac{d p^{D E *}}{d \alpha}<0$.

Proposition 3 illustrates that as the percentage of government eco-input subsidies to the manufacturer increases, the manufacturer will increase the eco-level of product, but will reduce the recycling transfer price and the third-party recycler's recycling price will also decrease. This implies that under a demand-oriented product ecodesign strategy, a higher percentage of eco-input subsidy, while providing incentives for the manufacturer to invest in a higher level of product, may also reduce the incentives for the manufacturer and the third-party recycler to recycle waste eco-products. Proposition 3 also illustrates the effect of government eco-input subsidy policy on the manufacturer's wholesale price and retailer's sales price in relation to demand- and environment-oriented product ecodesign strategy. If the manufacturer's ecodesign is overly consumer-oriented, the manufacturer's wholesale price and retailer's selling price will increase as the percentage of government 
eco-input subsidy to the manufacturer increases; if the manufacturer's ecodesign is overly environment-oriented, the manufacturer's wholesale price and retailer's sales price will decrease as the percentage of government eco-input subsidy to the manufacturer increases. More specifically, if the manufacturer's ecodesign slightly favors the consumer side, the manufacturer's wholesale price will decrease but the retailer's selling price will increase as the government subsidizes the manufacturer's eco-input ratio; if the ecodesign slightly favors the environmental side, both the manufacturer's wholesale price and the retailer's selling price will decrease as the government subsidizes the manufacturer's eco-input ratio.

Proposition 4. $\frac{d \pi_{m}^{D E *}}{d \alpha}>0, \frac{d \pi_{r}^{D E *}}{d \alpha}>0$ and $\frac{d \pi_{t}^{D E *}}{d \alpha}<0$.

Proposition 4 shows that as the percentage of eco-input subsidy increases, the manufacturer and retailer will gain more profit, but the third-party recycler will lose profit. In other words, under the demand-oriented product ecodesign strategy, government subsidy for the manufacturer's eco-inputs benefit himself and the retailer, but disadvantage the third-party recycler.

\subsection{Sales Subsidy Policy}

Under the government-imposed punitive recycling regulation, in order to incentivize the retailer to sell eco-products, the government will give the retailer a subsidy with s. Combining the profit functions of the supply chain members in the case without government subsidy, the profit functions of the manufacturer, the retailer, and the third-party recycler under the sales subsidy are:

$$
\begin{gathered}
\pi_{m}^{D S}=(w-c) q-\theta e^{2}-\mu R-(k-\delta e)(q-R) \\
\pi_{r}^{D S}=(p-w+s) q \\
\pi_{t}^{D S}=(\mu-\tau) R
\end{gathered}
$$

Through the above profit function of each decision maker in the supply chain, combined with consumer surplus and environmental pollution caused by unrecycled waste, and considering the government sales subsidy to the retailer, the social welfare function of the government is obtained as follows:

$$
\pi_{g}^{D S}=\pi_{m}^{D S}+\pi_{r}^{D S}+\pi_{t}^{D S}+\frac{q^{2}}{2}-(\varepsilon-k)(q-R)-s q
$$

In Equation (28), the last term on the right-hand side of the equation is the total government sales subsidy to the retailer.

Lemma 3. The manufacturer's profit maximization condition regarding the level of ecodesign is $\theta>\theta^{D S}=\frac{(\eta+\delta)^{2}+\lambda \delta^{2}}{8}=\theta^{D N}$.

This leads to the following optimal product ecodesign level for the manufacturer at that time:

$$
e^{D S *}=\frac{(1-c-k+s)(\eta+\delta)-\lambda \delta k}{8 \theta-(\eta+\delta)^{2}-\lambda \delta^{2}}
$$

Combining the above, the optimal pricing decision of each supply chain entity under the government sales subsidy policy can be obtained as:

$$
w^{D S *}=\frac{(8(1+k+c+s) \theta-2(\eta+\delta)(c \eta+\eta k+\delta+\delta s)-\lambda \delta(c \delta+\delta s+k \eta+\delta))}{2\left(8 \theta-(\eta+\delta)^{2}-\lambda \delta^{2}\right)},
$$




$$
\begin{gathered}
\mu^{D S *}=\frac{8 k \theta-(\eta+\delta)(\delta-c \delta+k \eta+\delta s)}{2\left(8 \theta-(\eta+\delta)^{2}-\lambda \delta^{2}\right)} \\
p^{D S *}=\frac{(8(3+k+c-s) \theta-4(\eta+\delta)(c \eta+\eta k+\delta-\eta s)-\lambda \delta(c \delta+3 \eta k+3 \delta-\delta s))}{4\left(8 \theta-(\eta+\delta)^{2}-\lambda \delta^{2}\right)} \\
\tau^{D S *}=\frac{8 k \theta-(\eta+\delta)(\delta-c \delta+\eta k+\delta s)}{4\left(8 \theta-(\eta+\delta)^{2}-\lambda \delta^{2}\right)}
\end{gathered}
$$

Further, the optimal profits for the manufacturer, the retailer and the third-party recycler under government sales subsidy can be obtained as:

$$
\begin{gathered}
\pi_{m}^{D S *}=\frac{8\left((1-c-k+s)^{2}+\lambda k^{2}\right) \theta-\lambda(\delta-c \delta+k \eta+\delta s)^{2}}{8\left(8 \theta-(\eta+\delta)^{2}-\lambda \delta^{2}\right)}, \\
\pi_{r}^{D S *}=\frac{(8(1-c-k+s) \theta-\lambda \delta(\delta-c \delta+k \eta+\delta s))^{2}}{16\left(8 \theta-(\eta+\delta)^{2}-\lambda \delta^{2}\right)^{2}} \\
\pi_{t}^{D S *}=\frac{(8 k \theta-(\eta+\delta)(\delta-c \delta+\delta s+k \eta))^{2} \lambda}{16\left(8 \theta-(\eta+\delta)^{2}-\lambda \delta^{2}\right)^{2}}
\end{gathered}
$$

By conducting a sensitivity analysis of the optimal decision and optimal profit of each member of the supply chain regarding the government sales subsidy s, the impact of the government sales subsidy policy on the decision and profit of the supply chain members can be investigated, as shown in Proposition 5 and Proposition 6 below.

Proposition 5. $\frac{d e^{D S *}}{d s}>0, \frac{d w^{D S *}}{d s}>0, \frac{d \mu^{D S *}}{d s}<0, \frac{d p^{D S *}}{d s}<0$ and $\frac{d \tau^{D S *}}{d s}<0$.

Proposition 5 illustrates that as government sales subsidy payments to the retailer increase, the manufacturer will increase the ecological level of the product and wholesale price but will reduce the recycling transfer price to the third-party recycler, and both the retailer and the third-party recycler will reduce the pricing. Proposition 5 implies that government sales subsidy directly incentivizes the retailer to lower the sales price in order to sell more eco-products, while the subsidy policy also indirectly incentivizes the manufacturer to ecodesign the products and increase eco-product pricing. At the same time, due to the increase in the ecological level of product, the cost of environmental pollution decreases, thus there is a decrease in the manufacturer's recycling transfer price, which in turn will influence the third-party recycler to reduce the recycling price of waste eco-products. Thus, Proposition 5 reveals that while the government sales subsidy may incentivize the retailer to sell more eco-products and increase the eco-level of products, they will reduce the incentive for the third-party recycler to recycle waste products, which may result in more eco-products being sold but less being recycled, i.e., more unrecycled products, which in turn may lead to more environmental pollution.

Proposition 6. $\frac{d \pi_{m}^{D S *}}{d s}>0, \frac{d \pi_{r}^{D S *}}{d s}>0$ and $\frac{d \pi_{t}^{D S *}}{d s}<0$.

Proposition 6 shows that with the increase in government sales subsidy, the manufacturer and the retailer will gain more profits, but the third-party recycler will lose profits. In other words, the government sales subsidy to the retailer benefits the manufacturer and retailer, but disadvantages the third-party recycler.

\subsection{Consumption Subsidy Policy}

Under the government's implementation of punitive recycling regulation, in order to incentivize consumers to purchase eco-products, the government will provide consumption 
subsidy to consumers who purchase eco-products with $b$. From this, the sales volume function under the consumption subsidy can be obtained as $q=1-p+\eta e+b$. Further, the profit functions of the manufacturer, the retailer and the third-party recycler are:

$$
\begin{gathered}
\pi_{m}^{D B}=(w-c)(1-p+\eta e+b)-\theta e^{2}-\mu R-(k-\delta e)(1-p+\eta e+b-R), \\
\pi_{r}^{D B}=(p-w)(1-p+\eta e+b), \\
\pi_{t}^{D B}=(\mu-\tau) R .
\end{gathered}
$$

Further, through the above profit function of each decision maker in the supply chain, combined with the consumer surplus and environmental pollution caused by unrecycled waste, and considering the government's consumption subsidy for consumers who purchase eco-products, the social welfare function of the government can be obtained as follows:

$$
\pi_{g}^{D B}=\pi_{m}^{D B}+\pi_{r}^{D B}+\pi_{t}^{D B}+\frac{(1-p+\eta e+b)^{2}}{2}-(\varepsilon-k)(1-p+\eta e+b-R)-b(1-p+\eta e+b),
$$

In Equation (40), the last term on the right-hand side of the equation is the government consumption subsidy for consumers who purchase eco-products.

Lemma 4. The manufacturer's profit maximization condition regarding the level of ecodesign is $\theta>\theta^{D B}=\frac{(\eta+\delta)^{2}+\lambda \delta^{2}}{8}=\theta^{D N}=\theta^{D S}$.

This leads to the following optimal product ecodesign level for the manufacturer:

$$
e^{D B *}=\frac{(1-c-k)(\eta+\delta)-\lambda \delta k}{8 \theta-(\eta+\delta)^{2}-\lambda \delta^{2}}
$$

Combining the above, the optimal pricing decision of each supply chain entity under the government consumption subsidy policy can be obtained as:

$$
\begin{gathered}
w^{D B *}=\frac{(8(1+k+c+b) \theta-2(\eta+\delta)(b \delta+c \eta+\eta k+\delta)-\lambda \delta(c \delta-k \eta+\delta+\delta b))}{2\left(8 \theta-(\eta+\delta)^{2}-\lambda \delta^{2}\right)} \\
p^{D B *}=\frac{8 k \theta-(\eta+\delta)(\delta-c \delta+k \eta+\delta b)}{2\left(8 \theta-(\eta+\delta)^{2}-\lambda \delta^{2}\right)} \\
\tau^{D B *}=\frac{8 k \theta-(\eta+\delta)(\delta-c \delta+\eta k+\delta b)}{4\left(8 \theta-(\eta+\delta)^{2}-\lambda \delta^{2}\right)}
\end{gathered}
$$

Further, the optimal profits for the manufacturer, the retailer and the third-party recycler under government consumption subsidy can be obtained as:

$$
\begin{gathered}
\pi_{m}^{D B *}=\frac{8\left((1-c-k+b)^{2}+\lambda k^{2}\right) \theta-\lambda(\delta-c \delta+k \eta+\delta b)^{2}}{8\left(8 \theta-(\eta+\delta)^{2}-\lambda \delta^{2}\right)}, \\
\pi_{r}^{D B *}=\frac{(8(1-k-c+b) \theta-\lambda \delta(\delta-c \delta++\delta b+k \eta))^{2}}{16\left(8 \theta-(\eta+\delta)^{2}-\lambda \delta^{2}\right)^{2}}, \\
\pi_{t}^{D B *}=\frac{(8 k \theta-(\eta+\delta)(\delta-c \delta+k \eta))^{2} \lambda}{16\left(8 \theta-(\eta+\delta)^{2}-\lambda \delta^{2}\right)^{2}} .
\end{gathered}
$$


By conducting a sensitivity analysis of the optimal decision and optimal profit of each member of the supply chain regarding the government sales subsidy s, the impact of the government consumption subsidy policy on the decision and profit of the supply chain members can be studied, as shown in Proposition 7 and Proposition 8 below.

Proposition 7. $\frac{d e^{D B *}}{d b}>0, \frac{d w^{D B *}}{d b}>0, \frac{d \mu^{D B *}}{d b}<0, \frac{d p^{D B *}}{d b}>0$ and $\frac{d \tau^{D B *}}{d b}<0$.

Proposition 7 illustrates that as consumer subsidy increases, the manufacturer will increase product ecodesign levels and the wholesale product price, but will reduce recycling transfer price for the third-party recycler, the retailer will increase the sales price, and the third-party recycler will reduce the recycling price. Proposition 7 also implies that under the government's consumer subsidy policy, the retailer will erode part of consumers' subsidy by raising sales price. Additionally, the consumer subsidy policy stimulates purchasers and indirectly motivates the manufacturer to design the products ecologically and ensures that the manufacturer has higher pricing for the eco-products. However, it is possible that the increased level of ecology reduces the cost of environmental pollution, leading to a lower recycling transfer price for the manufacturer, which in turn influences the third-party recycler to reduce the recycling price of discarded ecological products.

Proposition 8. $\frac{d \pi_{m}^{D B *}}{d b}>0, \frac{d \pi_{r}^{D B *}}{d b}>0$ and $\frac{d \pi_{t}^{D B *}}{d b}<0$.

Proposition 8 reveals that with the increase in government consumption subsidy, the manufacturer and the retailer will gain more profits, but the third-party recycler will lose profits. In other words, the government consumption subsidy for consumers who purchase eco-products benefit the manufacturer and retailer, but disadvantage the thirdparty recycler.

\subsection{Recycling Subsidy Policy}

Under the government's punitive recycling regulation, in order to incentivize the third-party recycler to recycle waste eco-products, the government will give the third-party recycler a unit of recycling subsidy of $f$. Combining the profit functions of supply chain members in the absence of government subsidy, the profit functions of the manufacturer, the retailer, and the third-party recycler under the recycling subsidy are:

$$
\begin{gathered}
\pi_{m}^{D F}=(w-c) q-\theta e^{2}-\mu R-(k-\delta e)(q-R), \\
\pi_{r}^{D F}=(p-w) q, \\
\pi_{t}^{D F}=(\mu-\tau+f) R .
\end{gathered}
$$

In Equation (51), the term on the right side of the equation comes from the recycling subsidy from the government in addition to the profits derived from the manufacturer's recycling transfer.

Through the above profit function of each decision maker in the supply chain, combined with consumer surplus and environmental pollution caused by the unrecycled waste, and considering the government's recycling subsidy to the third-party recycler, the government's social welfare function can be obtained as follows:

$$
\pi_{g}^{D F}=\pi_{m}^{D F}+\pi_{r}^{D F}+\pi_{t}^{D F}+\frac{q^{2}}{2}-(\varepsilon-k)(q-R)-f R,
$$

In Equation (52), the last term on the right-hand side of the equation is the total government recycling subsidy to the third-party recycler. 
Lemma 5. The manufacturer's profit maximization condition regarding the level of ecodesign is $\theta>\theta^{D F}=\frac{(\eta+\delta)^{2}+\lambda \delta^{2}}{8}=\theta^{D N}$.

This leads to the following optimal product ecodesign level for the manufacturer:

$$
e^{D F *}=\frac{(1-c-k)(\eta+\delta)-\lambda \delta k(k+f)}{8 \theta-(\eta+\delta)^{2}-\lambda \delta^{2}},
$$

Combining the above, the optimal pricing decision of each supply chain entity under the government recycling subsidy policy can be obtained as:

$$
\begin{gathered}
w^{D F *}=\frac{(8(1+k+c) \theta-2(\eta+\delta)(c \eta+\eta k+\delta)-\lambda \delta(c \delta+k \eta+\delta-\delta f+\eta f))}{2\left(8 \theta-(\eta+\delta)^{2}-\lambda \delta^{2}\right)}, \\
\mu^{D F *}=\frac{8(k-f) \theta-(\eta+\delta)(\delta-c \delta+k \eta-\delta f-\eta f)+2 \delta^{2} \lambda f}{2\left(8 \theta-(\eta+\delta)^{2}-\lambda \delta^{2}\right)}, \\
p^{D F *}=\frac{(8(3+k+c) \theta-4(\eta+\delta)(c \eta+\eta k+\delta)-\lambda \delta(c \delta+3 \eta k+3 \delta-\delta f+3 \eta f))}{4\left(8 \theta-(\eta+\delta)^{2}-\lambda \delta^{2}\right)}, \\
\tau^{D F *}=\frac{8(k+f) \theta-(\eta+\delta)(\delta-c \delta+\eta k+\delta f+\eta f)}{4\left(8 \theta-(\eta+\delta)^{2}-\lambda \delta^{2}\right)} .
\end{gathered}
$$

Further, the optimal profits for the manufacturer, the retailer and the third-party recycler under government recycling subsidy can be obtained as:

$$
\begin{gathered}
\pi_{m}^{D F *}=\frac{8\left((1-c-k)^{2}+\lambda(k+f)^{2}\right) \theta-\lambda(\delta-c \delta+k \eta+\delta f+\eta f)^{2}}{8\left(8 \theta-(\eta+\delta)^{2}-\lambda \delta^{2}\right)}, \\
\pi_{r}^{D F *}=\frac{(8(1-k-c) \theta-\lambda \delta(\delta-c \delta+k \eta+\delta f+\eta f))^{2}}{16\left(8 \theta-(\eta+\delta)^{2}-\lambda \delta^{2}\right)^{2}}, \\
\pi_{t}^{D F *}=\frac{(8(k+f) \theta-(\eta+\delta)(\delta-c \delta+k \eta+\delta f+\eta f))^{2} \lambda}{16\left(8 \theta-(\eta+\delta)^{2}-\lambda \delta^{2}\right)^{2}} .
\end{gathered}
$$

By conducting a sensitivity analysis of the optimal decision and profit of each member of the supply chain regarding the government recycling subsidy $f$, the impact of the government recycling subsidy policy on the decision and profit can be studied, as shown in Proposition 9 and Proposition 10.

\section{Proposition 9.}

(i) $\frac{d e^{D F *}}{d f}<0, \frac{d \mu^{D F *}}{d f}<0$ and $\frac{d \tau^{D F *}}{d f}>0$.

(ii) if $\eta \geq \delta$, then $\frac{d w^{D E *}}{d f} \leq 0$, otherwise $\frac{d w^{D E *}}{d f}>0$;

(iii) if $\eta \geq \frac{\delta}{3}$, then $\frac{d p^{D E *}}{d f} \leq 0$, otherwise $\frac{d p^{D E *}}{d f}>0$.

Proposition 9 illustrates that as government recycling subsidy to the third-party recycler increases, the manufacturer will reduce the eco-level of the product and recycling transfer price, while they will increase recycling price for the third-party recycler. Proposition 9 also illustrates the effect of government recycling subsidy policy on the manufacturer's wholesale price and retailer's sales price in relation to demand- and environment-oriented product ecodesign strategy. If the manufacturer's ecodesign is overly biased toward the environmental side, the manufacturer's wholesale price and the retailer's sales price will 
increase as government recycling subsidy to the third-party recycler increases; if the ecodesign is overly biased toward the consumer side, the wholesale price and selling price will decrease as government recycling subsidy to third-party recyclers increases. More specifically, if the manufacturer's ecodesign slightly favors the environmental side, the manufacturer's wholesale price will decrease, but the retailer's sales price will increase as government recycling subsidy to third-party recyclers increases; if the ecodesign slightly favors the consumer side, both of them will decrease.

Proposition 10. $\frac{d \pi_{m}^{D F *}}{d f}>0, \frac{d \pi_{r}^{D F *}}{d f}<0$ and $\frac{d \pi_{t}^{D F *}}{d f}>0$.

Proposition 10 shows that as government recycling subsidy increases, the manufacturer and the third-party recycler will reap more profits, but the retailer's profits will suffer. That is, government recycling subsidy for the third-party recycler will benefit the manufacturer and the third-party recycler, but not the retailer.

\section{Comparative Analysis}

This section will compare the eco-level of the product and the optimal profits of supply chain members under four types of government subsidy (eco-input subsidy, sales subsidy, consumption subsidy, and recycling subsidy), using no government subsidy as the base case, to explore how government subsidy affects the eco-level of product and the profits of supply chain members when the manufacturer implements a demand-oriented product ecodesign strategy.

Corollary 1. $e^{D E *}, e^{D S *}, e^{D B *}>e^{D N *}>e^{D F *}$.

Corollary 1 illustrates that among the five government policies, the government recycling subsidy policy will result in the lowest eco-level of product. Except for the recycling subsidy policy, the other three subsidy policies can increase the eco-level of product, which implies that the manufacturer maintains a very low level of product ecodesign under the recycling subsidy policy. Therefore, this policy is not conducive to demand-oriented product ecodesign. Corollary 1 also illustrates that although a government subsidy policy such as eco-input subsidy, sales subsidy, or consumption subsidy can improve the manufacturer's eco-level of product compared to the no-subsidy policy, it is unclear which subsidy policy has a higher eco-level, and for this reason a further comparative analysis of the manufacturer's optimal eco-level of the product under these three subsidy policies is conducted through Corollary 2.

\section{Corollary 2.}

(i) if $\alpha \geq \frac{y_{2}(s)}{y_{1}(s)}$, then $e^{D E *} \geq e^{D S *}$, otherwise $e^{D E *}<e^{D S *}$;

(ii) if $\alpha \geq \frac{y_{4}(b)}{y_{3}(b)}$, then $e^{D E *} \geq e^{D B *}$, otherwise $e^{D E *}<e^{D B *}$;

(iii) if $s \geq b$, then $e^{D S *} \geq e^{D B *}$, otherwise $e^{D S *}<e^{D B *}$.

where $y_{1}(s)=8 \theta(\delta+\eta)(1-c-k+s)$;

$y_{2}(s)=s(\delta+\eta)\left(8 \theta-\delta^{2} \lambda-\delta^{2}-2 \delta \eta-\eta^{2}\right)$;

$y_{3}(b)=8 \theta(\delta+\eta)(1-c-k+b)$;

$y_{4}(b)=b(\delta+\eta)\left(8 \theta-\delta^{2} \lambda-\delta^{2}-2 \delta \eta-\eta^{2}\right)$.

Corollary 2 illustrates that the ecological level of the manufacturer's product under three government subsidy policies, such as eco-input subsidy, sales subsidy, and consumption subsidy, depends on the corresponding percentage and amount of subsidy. Specifically, for a certain amount of government sales and consumption subsidy, there is a certain threshold of the percentage eco-input subsidy, such that when the government's eco-input 
subsidy percentage is greater than this threshold, the manufacturer's eco-level of product is highest under eco-input subsidy; on the contrary, if the eco-input subsidy is less than a certain threshold, the eco-level of the manufacturer's product under eco-input subsidy is the lowest compared with the other two subsidy policies. Corollary 2 also illustrates that the comparison of the manufacturer's eco-level of product under the government's sales subsidy policy with that under the consumption subsidy policy depends entirely on the corresponding amount of subsidy, independent of the other parameters, i.e., whichever subsidy policy has a high subsidy payment, the corresponding eco-level of the product is high.

\section{Corollary 3.}

(i) $\pi_{m}^{D E *}, \pi_{m}^{D S *}, \pi_{m}^{D B *}, \pi_{m}^{D F *}>\pi_{m}^{D N *}$;

(ii) $\pi_{r}^{D E *}, \pi_{r}^{D S *}, \pi_{r}^{D B *}>\pi_{r}^{D N *}>\pi_{r}^{D F *}$;

(iii) $\pi_{t}^{D E *}, \pi_{t}^{D S *}, \pi_{t}^{D B *}, \pi_{t}^{D F *}<\pi_{t}^{D N *}$.

Corollary 3 illustrates that whatever subsidy policy the government implements will benefit the manufacturer but disadvantage the third-party recycler compared to the nosubsidy policy, and among the effects on the retailer, the government's recycling subsidy policy will result in the lowest profits for the retailer.

\section{Corollary 4.}

(i) if $\alpha \geq \frac{H_{2}(s)}{H_{1}(s)}$, then $\pi_{m}^{D E *} \geq \pi_{m}^{D S *}$, otherwise $\pi_{m}^{D E *}<\pi_{m}^{D S *}$;

(ii) if $\alpha \geq \frac{H_{4}(b)}{H_{3}(b)}$, then $\pi_{m}^{D E *} \geq \pi_{m}^{D B *}$, otherwise $\pi_{m}^{D E *}<\pi_{m}^{D B *}$;

(iii) if $\alpha \geq \frac{H_{6}(f)}{H_{5}(f)}$, then $\pi_{m}^{D E *} \geq \pi_{m}^{D F *}$, otherwise $\pi_{m}^{D E *}<\pi_{m}^{D F *}$.

where $H_{1}(s)=8 \theta\left(\left(8 \theta-\lambda \delta^{2}\right) s^{2}+B_{1} s+((\sigma+\delta)(1-c-k)-\lambda \delta k)^{2}>0\right.$;

$H_{2}(s)=\left(8 \theta-\lambda \delta^{2}\right)\left(8 \theta-(\eta+\delta)^{2}-\lambda \delta^{2}\right) s^{2}+B_{2} s>0$;

$H_{3}(b)=8 \theta\left(8 \theta-\delta^{2} \lambda\right) b^{2}+B_{1} b+8 \theta((\eta+\delta)(1-c-k)-\delta k \lambda)^{2}>0 ;$

$H_{4}(b)=\left(8 \theta-\lambda \delta^{2}\right)\left(8 \theta-(\eta+\delta)^{2}-\lambda \delta^{2}\right) b^{2}+B_{2} b>0 ;$

$H_{5}(f)=8 \theta\left(\lambda\left(8 \theta-(\eta+\delta)^{2}\right) f^{2}+8 \theta \lambda B_{3} f+8 \theta((\eta+\delta)(1-c-k)-\lambda \delta k)^{2}\right)>0$;

$H_{6}(f)=\lambda\left(8 \theta-(\eta+\delta)^{2}\right)\left(8 \theta-(\eta+\delta)^{2}-\lambda \delta^{2}\right) f^{2}-\lambda B_{4} f>0$;

$B_{1}=16 \theta(8 \theta(1-c-k)-\delta \lambda(c \delta-\eta k-\delta))$;

$B_{2}=2\left(8 \theta-(\eta+\delta)^{2}-\lambda \delta^{2}\right)(8 \theta(1-c-k)+\delta \lambda(c \delta-\eta k-\delta))$;

$B_{3}=2(8 k \theta-(\eta+\delta)(\delta-c \delta+k \eta))$;

$B_{4}=2\left(8 \theta-(\eta+\delta)^{2}\right)(8 k \theta-(\eta+\delta)(\delta-c \delta+k \eta))$.

Corollary 4 shows that under demand-oriented product ecodesign strategy, if the government sales subsidy, consumption subsidy and recycling subsidy are certain, there is always a critical value of eco-input subsidy such that when it is greater than this value, the government eco-input subsidy policy makes the manufacturer the most profitable; conversely, there is also a critical value of eco-input subsidy such that when it is less than this value, the manufacturer's profit under the government eco-input subsidy policy is the lowest among all subsidies.

\section{Corollary 5.}

(i) if $s \geq b$, then $\pi_{m}^{D S *} \geq \pi_{m}^{D B *}$, otherwise $\pi_{m}^{D S *}<\pi_{m}^{D B *}$;

(ii) if $H_{7}(s) \geq H_{8}(f)$, then $\pi_{m}^{D S *} \geq \pi_{m}^{D F *}$, otherwise $\pi_{m}^{D S *}<\pi_{m}^{D F *}$;

(iii) if $H_{9}(b) \geq H_{8}(f)$, then $\pi_{m}^{D B *} \geq \pi_{m}^{D F *}$, otherwise $\pi_{m}^{D B *}<\pi_{m}^{D F *}$.

where $H_{7}(s)=\left(8 \theta-\lambda \delta^{2}\right) s^{2}+2(8(1-c-k) \theta-\lambda \delta(\delta-c \delta+k \eta)) s>0$;

$H_{8}(f)=\lambda\left(8 \theta-(\eta+\delta)^{2}\right) f^{2}+2 \lambda(8 k \theta-(\eta+\delta)(\delta-c \delta+k \eta)) f>0$; 
$H_{9}(b)=\left(8 \theta-\lambda \delta^{2}\right) b^{2}+2(8(1-c-k) \theta-\lambda \delta(\delta-c \delta+k \eta)) b>0$.

Corollary 5 illustrates that the relationship between the size of the manufacturer's optimal profit under the government's sales subsidy and consumer subsidy policy in the demand-oriented product ecodesign strategy depends entirely on the corresponding subsidy payments, and that the manufacturer's corresponding profit is higher for whichever subsidy is higher. In conjunction with Corollary 4 , Corollary 5 also shows that there exists a certain critical sales subsidy amount (or consumption subsidy amount) under a certain percentage of government eco-input subsidy, consumption subsidy amount (or sales subsidy amount), and recycling subsidy, such that the manufacturer's optimal profit under the government sales subsidy policy (or consumption subsidy policy) is highest when the sales subsidy amount (or consumption subsidy amount) is greater than this critical value. Similarly, there is a critical recycling subsidy value under a certain percentage of the government eco-input subsidy, the amount of consumption subsidy and sales subsidy, such that the manufacturer's optimal profit under the government recycling subsidy policy is the highest when the recycling subsidy is greater than this critical value.

\section{Numerical Analysis}

In this section, the impact of the manufacturer's product ecodesign, government subsidy policy and recycling regulation on supply chain members' decisions and the profits will be investigated through numerical calculations, and thus the impact on social welfare will be further studied. Specifically, it is divided into the effects of ecodesign, the effects of subsidy policies, and the effects of recycling regulations.

\subsection{The Impact of Ecodesign}

Due to the complexity of the model, the impact of product ecodesign is not analyzed in the model analysis section. Given that the demand-oriented product ecodesign strategy in this section is mainly reflected in the degree of impact on the increase in consumer utility, for this reason, the impact of $\eta$ on the decision making of supply chain members and their profits as well as government social welfare will be studied in the following section under certain other parameters, where the other parameters are assigned as: $c=0.3, \theta=5$, $k=0.2, \varepsilon=0.3, \lambda=1, \delta=0.5, \alpha=0.2, s=0.15, b=0.1, f=0.05$; the specific results are shown in Figures 1-4.

It can be seen in Figure 1 that the greater the effect of ecodesign on the degree of increased consumer utility in a demand-oriented ecodesign strategy, the higher the ecolevel of manufacturer input. However, the impact effects differ under different subsidy policies. Specifically, the demand-oriented product ecodesign is more sensitive to the influence of the optimal eco-level of the product under the policies of eco-input subsidy, sales subsidy, and consumer subsidy, and the effect is higher. Specifically, the effect is the largest under eco-input subsidy, while the effect is smaller for the optimal eco-level of the product under no subsidy and recycling subsidy. Figure 1 implies that under a demand-oriented product ecodesign strategy, government implementation of eco-input compensation may provide more incentive for the manufacturer to improve the eco-level of the product, while traditional recycling subsidy policy provides little incentive to do so.

Figure 2 shows that the demand-oriented product ecodesign will reduce recycling transfer price of the manufacturer and recycling price of the third-party recycler, but will have a variable impact on the manufacturer's wholesale price and retailer's sales price. If the eco-level of the product has a small impact on consumer utility, the wholesale price and sales price under the policies of eco-input subsidy, sales subsidy, and consumption subsidy will decrease with the increase in this impact, and the wholesale price and sales price under the recycling subsidy policy will increase with the increase in this impact; however, if the eco-level of the product has a greater impact on the consumer's utility, the wholesale and sales price under the policies of eco-input subsidy, sales subsidy, and consumption subsidy 
will decrease with the increase in this influence, and the wholesale and sales price under the policy of recycling subsidy will increase with the increase in this influence.

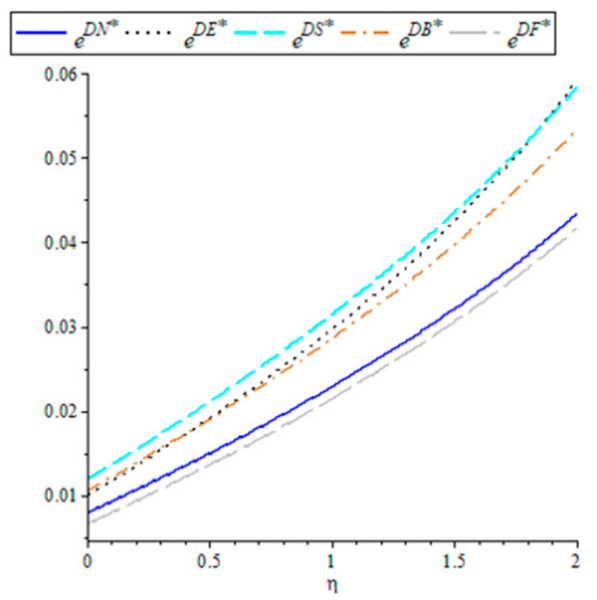

Figure 1. The effect of $\eta$ on the optimal eco-level of the manufacturer's product.

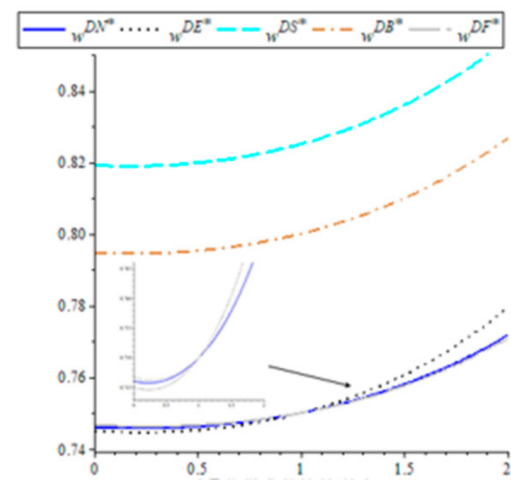

(a) The impact on wholesale price

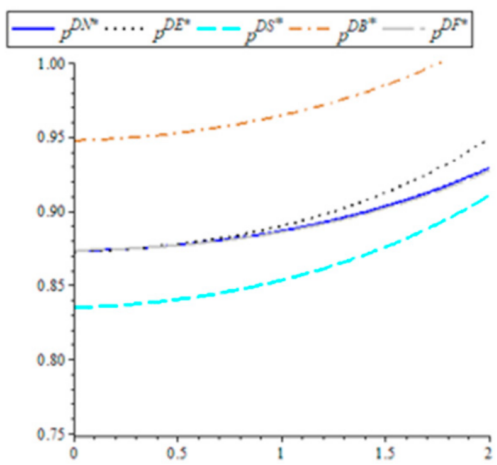

(c) The impact on sales price



(b) The impact on recovery transfer price

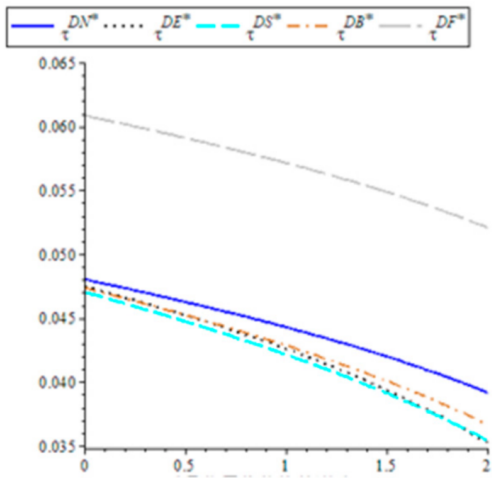

(d) The impact on recycling price

Figure 2. The impact of $\eta$ on the optimal pricing of supply chain members.

The first three subplots of Figure 3 reveal that demand-oriented product ecodesign benefits both the manufacturer and retailer, but disadvantages the third-party recycler, while the last subplot reveals that the strategy improves the overall supply chain performance. Figure 3 also reveals that as the impact of ecodesign on consumer utility increases, demand-oriented product ecodesign has the greatest impact on the profits of the manufacturer, the retailer, and the supply chain under eco-input subsidy, while the third subplot also reveals that demand-oriented product ecodesign has a greater impact on the profits of the third-party recycler under eco-subsidized inputs. 
Figure 4 shows that as the impact of product ecodesign on consumer utility increases, its social welfare increases regardless of the subsidy policy implemented by the government, with demand-oriented product ecodesign having the greatest impact on social welfare under sales subsidy and consumer subsidy, mainly because the impact on supply chain profits is also greater in these two cases and increases consumer surplus.

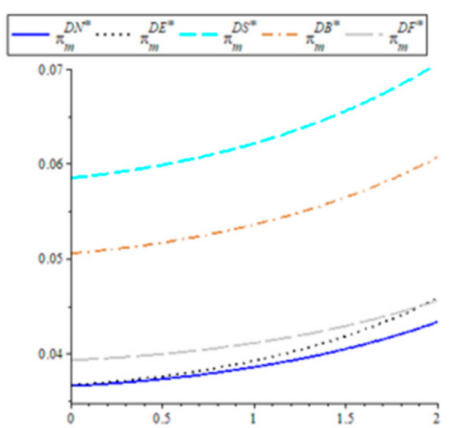

(a) The impact on the profit of manufacturer

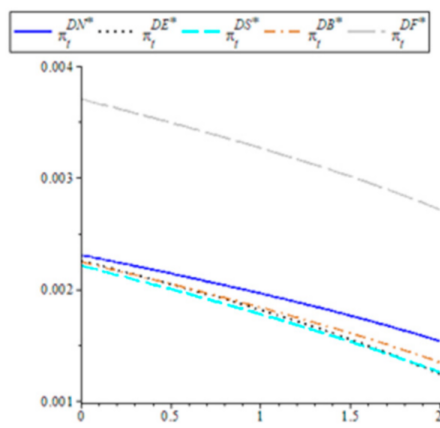

(c) The impact on the profit of third party

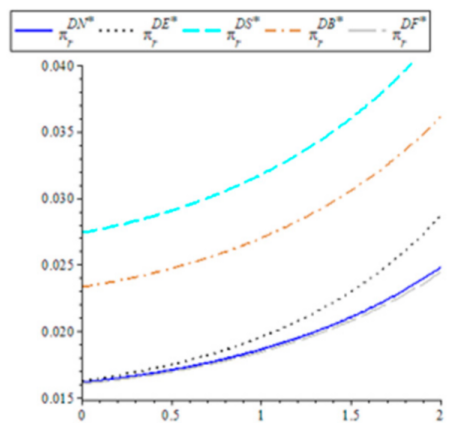

(b) The impact on the profit of retailer

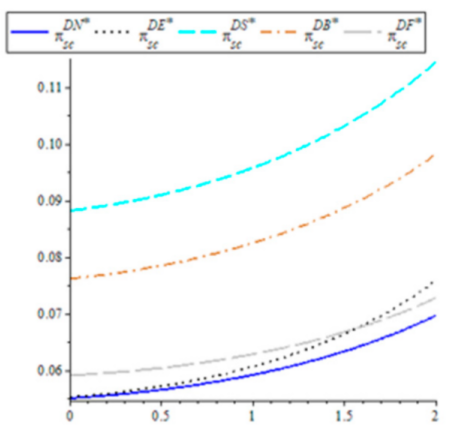

(d) The impact on the profit of supply chain

Figure 3. The impact of $\eta$ on the optimal profit of the supply chain and its members.

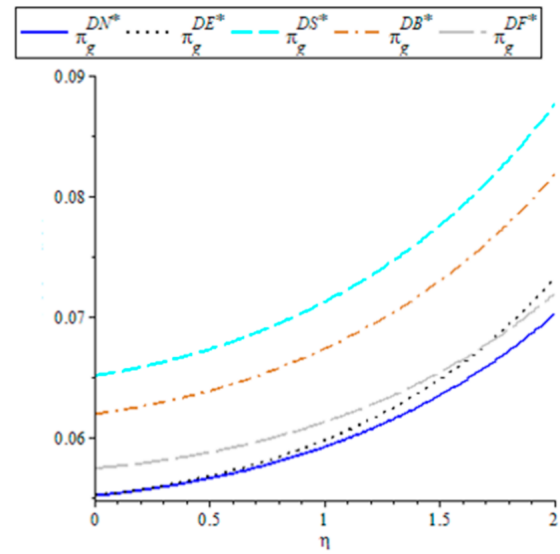

Figure 4. The impact of $\eta$ on social welfare.

\subsection{Impact of Subsidy Policy}

To investigate the impact of subsidy policies on the ecological design of demandoriented products, the main parameters are assigned the following values in this subsection: $c=0.3, \theta=5, k=0.2, \varepsilon=0.3, \lambda=1, \eta=1>\delta=0.5$. The specific results are shown in Figures 5-9.

Figure 5 shows the significant variability in the impact of different policies on the optimal decision of supply chain members under a demand-oriented product ecodesign strategy. First, government subsidy policies such as eco-input subsidy, sales subsidy, and consumption subsidy can improve the manufacturer's eco-level of the product, while 
government recycling subsidy can reduce the eco-level of product, with eco-input subsidy having the greatest impact on eco-level of the product. Then, among the four subsidy policies, two policies, sales subsidy and consumer subsidy, have the largest and most positive impact on the manufacturer's wholesale price. At the same time, both also have the greatest impact on the retailer's sales price, where the former has a negative impact and the latter has a positive impact. However, the two policies of eco-input subsidy and recycling subsidy have little effect on the manufacturer's wholesale price and retailer's selling price, with the former being weakly positively and the latter weakly negatively correlated with both types of pricing. Finally, the government's eco-input subsidy, sales subsidy policy and consumption subsidy policy have little effect on the manufacturer's recycling transfer price and the recycler's recycling price, and there is a weak negative correlation; while the government's recycling subsidy policy has a negative effect on the manufacturer's recycling transfer price but a positive effect on recyclers' recycling price, and both have a greater effect on them.

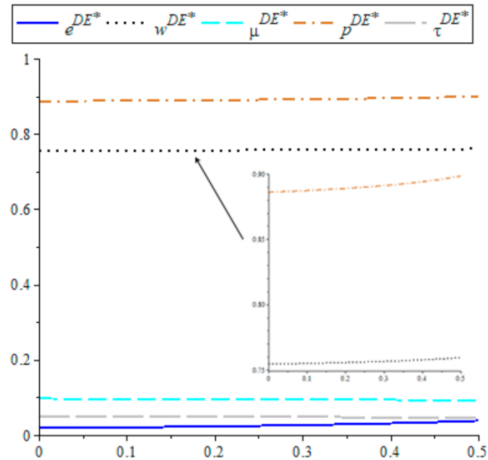

(a) The impact of $\alpha$

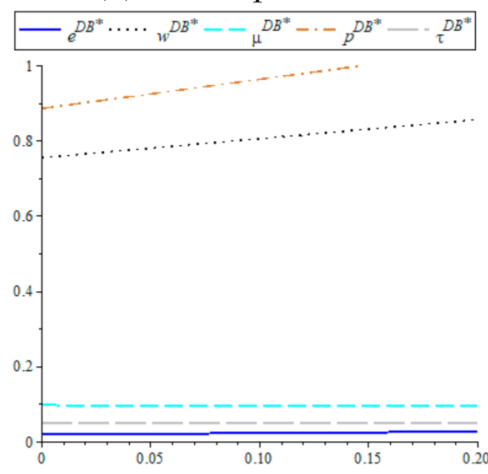

(c) The impact of $b$

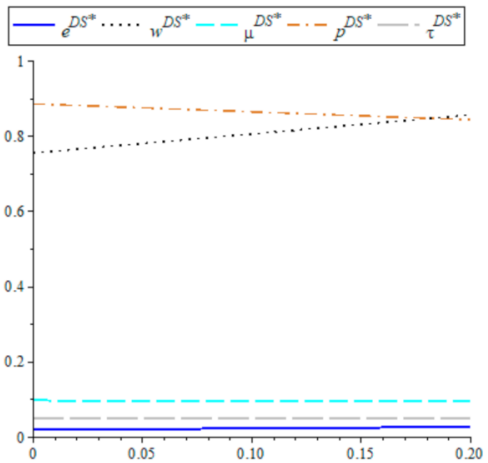

(b) The impact of $s$

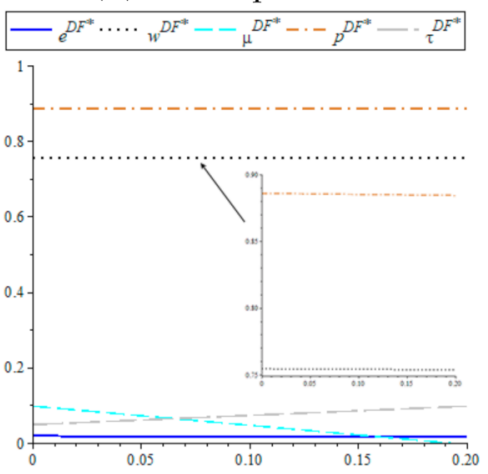

(d) The impact of $f$

Figure 5. The impact of subsidy policy on optimal decision making.

It can be seen in Figure 6 that under the demand-oriented product ecodesign strategy, either subsidy policy benefits the manufacturer and the retailer and increases profits throughout the supply chain, but the impact of different subsidy policies on the profits of the third-party recycler varies. Specifically, government sales subsidy and consumption subsidy are the most impactful on the manufacturer, the retailer, and overall supply chain profits, and the third-party recycler is the most affected by government recycling subsidy, which has a positive impact. However, the other three subsidies have little impact on the third-party recycler and have a weak negative correlation. Meanwhile, the government's eco-input subsidy has the least impact on the profitability of the supply chain and its members under the four subsidy policies.

It can be seen in Figure 7 that under the demand-oriented product ecodesign strategy, when the government has implemented the recycling regulation policy, the government then implements subsidy policies such as sales subsidy, consumption subsidy, and recycling subsidy, all of which will increase the welfare of the whole society, and the social welfare 
will increase with the amount of subsidy. However, under the government's eco-input subsidy policy, if the percentage of the government's subsidy is too high, it will reduce the welfare of the whole society, which implies that the government needs to effectively control the percentage of subsidy under the eco-input subsidy policy in order to make the policy play a better role.

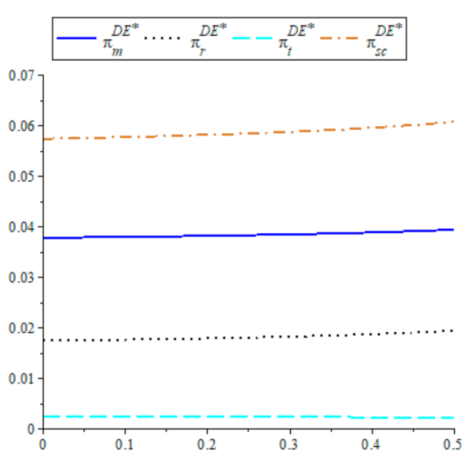

(a) The impact of $\alpha$



(c) The impact of $b$

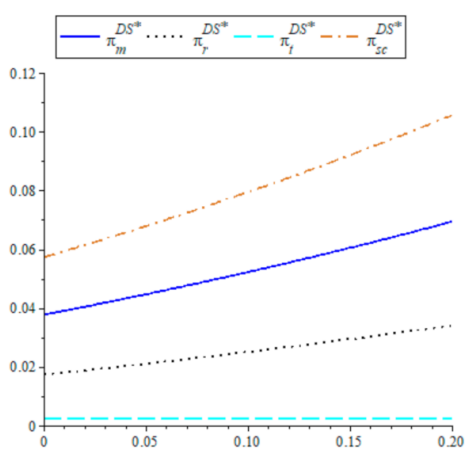

(b) The impact of $s$

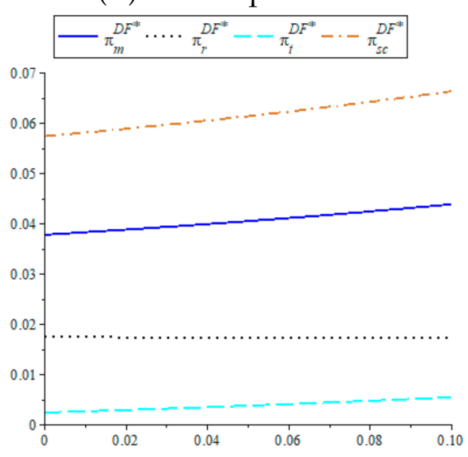

(d) The impact of $f$

Figure 6. The impact of subsidy policy on the optimal profit of the supply chain and its members.

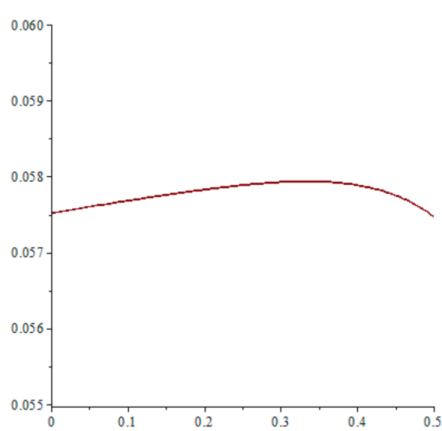

(a) The impact of $\alpha$

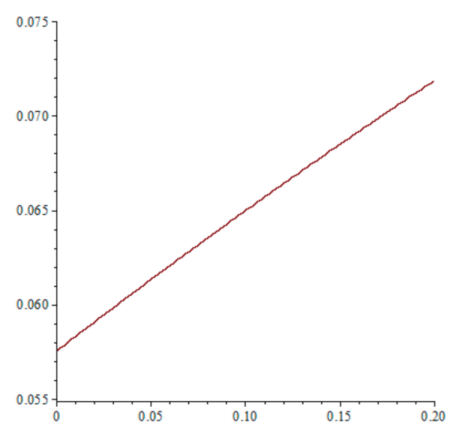

(c) The impact of $b$



(b) The impact of $s$

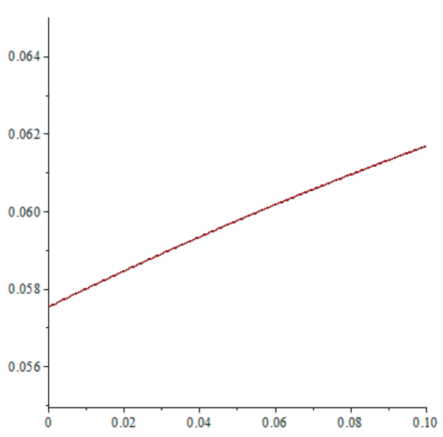

(d) The impact of $f$

Figure 7. The impact of subsidy policy on social welfare. 
Under the demand-oriented product ecodesign strategy, firstly, it can be seen in Figure $8 b$ that there is no difference in the impact of government sales subsidy policy and consumption subsidy policy on the supply chain and its members, which depends entirely on the respective subsidies, and for this reason, as can be seen in Figure $8 \mathrm{a}$, the sales subsidy policy and consumption subsidy policy may be more beneficial to the whole supply chain and its members than the government eco-input subsidy policy. Then, through Figure 8c, it can be seen that compared to the government recycling subsidy policy, the consumption subsidy policy and the sales subsidy policy are less differentiated for the manufacturer and the whole supply chain, but there is a dominant policy for the retailer and the third-party recycler, i.e., there is no indifference curve. Finally, Figure $8 \mathrm{~d}$ reveals that the recycling subsidy policy is favorable to the manufacturer compared to the government's eco-input subsidy policy, but the impact on the whole supply chain is larger first and then smaller, in addition, there is a dominant policy for the retailer and the third-party recycler, i.e., there is no indifference curve.

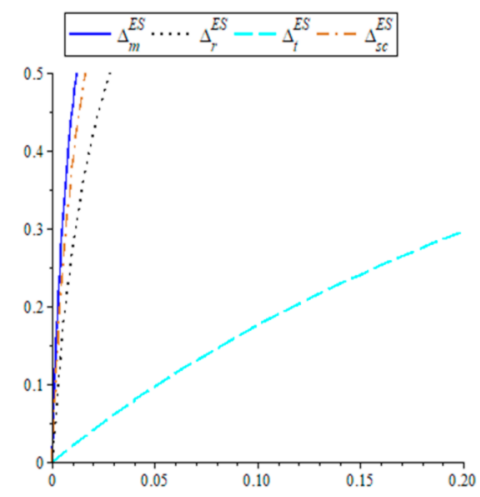

(a) The impact of $\alpha$ and $s$

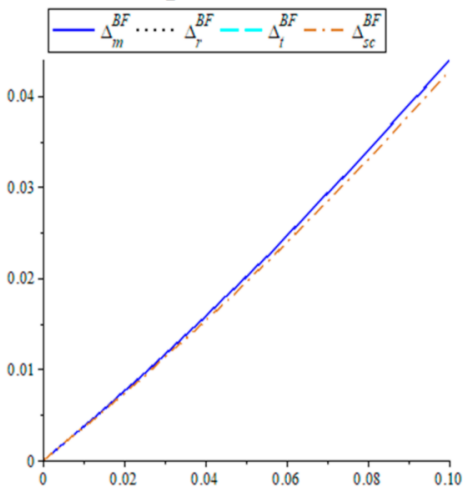

(c) The impact of $b$ and $f$

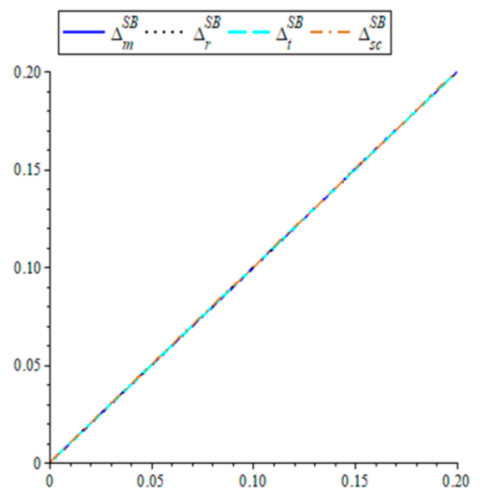

(b) The impact of $s$ and $b$

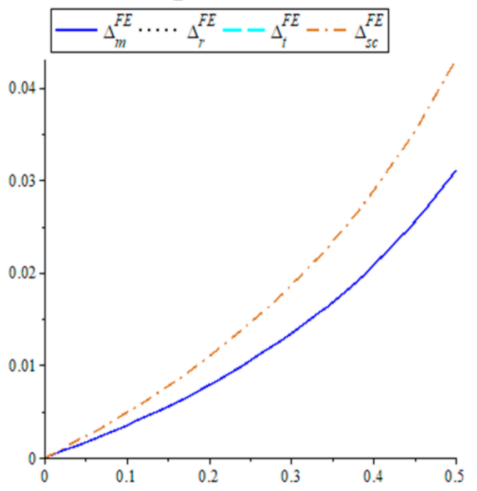

(d) The impact of $f$ and $\alpha$

Figure 8. Indifference in the optimal profit line under different subsidy policies.

Figure 9a,d show that the eco-input subsidy policy may be more beneficial to improving social welfare than the government's sales subsidy policy and recycling subsidy policy, especially when the proportion of the eco-input subsidy is not too low or too high, thus this policy may be more effective for allowing the government to improve social welfare. In addition, it can be seen in Figure $9 \mathrm{~b}$ that the adoption of a sales subsidy policy and consumption subsidy policy by the government has a nondifferential effect on social welfare, i.e., it is only related to the respective subsidy payments. It can also be seen in Figure 9c that the adoption of a recycling subsidy policy and consumption subsidy policy by the government has a similar effect on social welfare, with little difference. Overall, Figure 9 shows that among the four government subsidy policies under the demand-oriented product ecodesign strategy, the eco-input subsidy policy has the greatest effect on improving social welfare, which can provide some theoretical basis for the government to choose the appropriate subsidy policy regarding product ecodesign. 


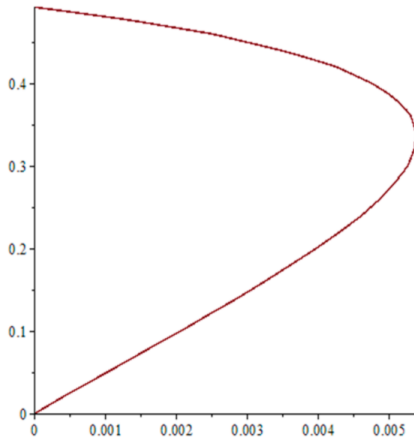

(a) The impact of $\alpha$ and $s$

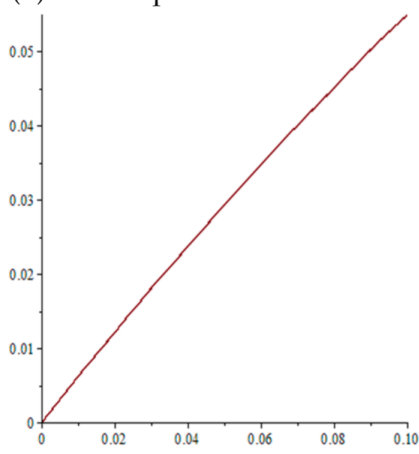

(c) The impact of $b$ and $f$

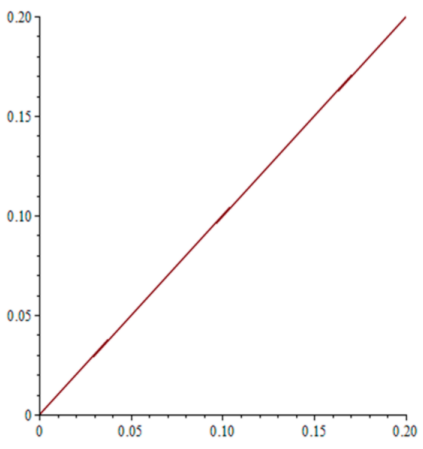

(b) The impact of $s$ and $b$

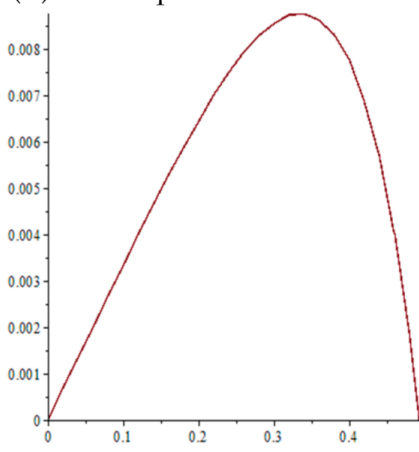

(d) The impact of $f$ and $\alpha$

Figure 9. Indifference in social welfare lines under different subsidy policies.

\section{Conclusions}

This paper considers that product ecodesign affects consumer utility, and thus market demand, and investigates demand-oriented ecodesign strategy for electrical and electronic products under government recycling regulations related to eco-level of the product. First, the government subsidy-free policy is used as the benchmark, and government subsidy policies such as eco-input subsidy, sales subsidy, consumption subsidy, and recycling subsidy are introduced, respectively, and the product ecodesign strategy model for the downward demand of each policy is established. Second, this paper uses the Stackelberg game theory and analysis, using the inverse method. Additionally, through the sensitivity analysis of optimal decision and profit of supply chain members under each scenario and comparison, this paper investigated how recycling regulation and subsidy policies of government affect the demand-oriented product ecodesign strategy using mathematical proof. Finally, considering the complexity of the model, the important conclusions in the model analysis are verified using numerical arithmetic analysis, and the related problems that cannot be proved by strict mathematical theory are also analyzed by numerical simulation. The main findings of this paper are as follows:

(1) Under no subsidy policy, as the penalty of government recycling regulation increases, the manufacturer will subsequently reduce the level of product ecodesign. In addition, the government's imposition of punitive recycling regulation will reduce the profits of the manufacturer who designs the products ecologically, and will also have a negative impact on the retailer. However, recycling regulation will benefit the third-party recycler;

(2) As eco-input subsidy, sales subsidy, and consumption subsidy increase, the level of product ecodesign increases, but recycling subsidy has a negative correlation with the level of product ecodesign;

(3) Under the demand-oriented product ecodesign strategy, the manufacturer' profits increase with the increase in all government subsidies; the retailer' profits increase with the increase in government eco-input subsidy, sales subsidy, and consumption subsidy, and decrease with the increase in recycling subsidy; the third-party recycler's 
profits decrease with the increase in government eco-input subsidy, sales subsidy, and consumption subsidy. The profit of the third-party recycler will decrease with the increase in government's eco-input subsidy, sales subsidy and consumption subsidy, and increase with the increase in recycling subsidy.

Product ecodesign in supply chain management is a new research field, and there are many new problems to be discussed. This paper only discusses some of the key problems, and it has some limitations and deficiencies. In the follow-up study, topics such as recycling channel structure and member competition will be further discussed and analyzed.

Author Contributions: Y.Z. supervised the whole research work. Q.W. raised the research question and wrote the manuscript. All authors have read and agreed to the published version of the manuscript.

Funding: This work is supported by the National Natural Science Foundation of China (No. 71974104).

Institutional Review Board Statement: The study was conducted according to the guidelines of the Declaration of Helsinki, and following the academic ethics.

Informed Consent Statement: Informed consent was obtained from all subjects involved in the study.

Data Availability Statement: Not applicable.

Acknowledgments: The authors especially thank the editors and anonymous referees for their kind review and helpful comments.

Conflicts of Interest: The authors declare no conflict of interest.

\section{Appendix A}

Proof of Lemma 1. Considering that the sales volume of the eco-product and recycling volume are independent of each other, and both the retailer and the third-party recycler are within the game, the game decisions of both will be considered here, then the sales volume function $q=1-p+\eta e$ and the recycling volume function $R=\lambda \tau$ are substituted into Equations (2) and (3), respectively, and it is easy to judge that the retailer profit function regarding the product price and the third-party recycler profit function regarding the recycling price are one-dimensional concave functions, then by the first-order condition the respective response functions can be obtained as follows:

$$
\begin{gathered}
p^{D N}=\frac{1+w+\eta e}{2} \\
\tau^{D N}=\frac{\mu}{2} .
\end{gathered}
$$

Substituting the above two equations into the manufacturer's profit function of Equation (1), we can obtain the manufacturer's profit function with respect to the wholesale price and the recovery transfer price as a binary concave function, and the respective reaction functions can be obtained from the first-order conditions as follows:

$$
\begin{gathered}
w^{D N}=\frac{1+k+c+\eta e-\delta e}{2}, \\
\mu^{D N}=\frac{k-\delta e}{2} .
\end{gathered}
$$

Substituting Equations (7) and (8) above into Equation (1), the manufacturer's profit maximization condition on the eco-level of the product is further obtained as:

$$
\theta>\theta^{D N}=\frac{(\eta+\delta)^{2}+\lambda \delta^{2}}{8}
$$


However, when $\theta \leq \theta^{D N}$, the manufacturer will have unlimited product eco-input, and this situation is not consistent with reality, so it will not be discussed. At the same time, the text involves a similar situation, which will not be repeated.

Proof of Proposition 1. Taking Equations (5)-(9), with respect to finding the first order derivative, we can obtain:

$$
\begin{aligned}
& \frac{d e^{D N *}}{d k}=-\frac{\eta+\delta+\lambda \delta}{8 \theta-(\eta+\delta)^{2}-\lambda \delta^{2}}<0, \\
& \frac{d w^{D N *}}{d k}=\frac{8 \theta-\lambda \delta \eta-2 \delta \eta-2 \eta^{2}}{2\left(8 \theta-(\eta+\delta)^{2}-\lambda \delta^{2}\right)}>0 . \\
& \frac{d \mu^{D N *}}{d k}=\frac{8 \theta-(\eta+\delta) \eta}{2\left(8 \theta-(\eta+\delta)^{2}-\lambda \delta^{2}\right)}>0 \\
& \frac{d p^{D N *}}{d k}=\frac{8 \theta-3 \lambda \delta \eta-4 \eta \delta-4 \eta^{2}}{4\left(8 \theta-(\eta+\delta)^{2}-\lambda \delta^{2}\right)}>0 \\
& \frac{d \tau^{D N *}}{d k}=\frac{8 \theta-(\eta+\delta) \sigma}{4\left(8 \theta-(\eta+\delta)^{2}-\lambda \delta^{2}\right)}>0
\end{aligned}
$$

Then, the proof is obtained from the above.

Proof of Proposition 2. Taking Equations (10)-(12), with respect to $k$ finding the first-order derivative, we can obtain:

$$
\begin{gathered}
\frac{d \pi_{m}^{D N *}}{d k}=-\frac{16(1-c-k-\lambda k) \theta-2 \lambda \eta(\delta-c \delta+k \eta)}{8\left(8 \theta-(\lambda+\delta)^{2}-\lambda \delta^{2}\right)}<0, \\
\frac{d \pi_{r}^{D N *}}{d k}=-\frac{(8 \theta+\delta \eta \lambda)(8(1-c-k) \theta-\lambda \delta(\delta-c \delta+k \eta))}{8\left(8 \theta-(\eta+\delta)^{2}-\lambda \delta^{2}\right)^{2}}<0 ; \\
\frac{d \pi_{t}^{D N *}}{d k}=\frac{(8 \theta-(\eta+\delta) \eta)(8 k \theta-(\eta+\delta)(\delta-c \delta+k \eta)) \lambda}{8\left(8 \theta-(\eta+\delta)^{2}-\lambda \delta^{2}\right)^{2}}>0 .
\end{gathered}
$$

Then, the proof is obtained from the above.

Proof of Lemma 2. Through the analysis of 3.1 on the solution process of each decision maker in the supply chain under the no-government subsidy policy, it can be found that the response functions of the retailer's sales price and the third-party recycler's recycling price under the government eco-input subsidy are consistent with the previous case. As a result, by substituting the sales volume function $q=1-p+\eta$ e and recycling volume function $R=\lambda \tau$ and Equations (A1) and (A2) into Equation (13), respectively, the reaction functions of the manufacturer's profit function with respect to the wholesale price and recycling transfer price are also consistent with the previous case. Further substituting Equations (A3) and (A4) into Equation (13) yields the manufacturer's profit maximization condition with respect to the level of ecodesign, as:

$$
\theta>\theta^{D E}=\frac{(\eta+\delta)^{2}+\lambda \delta^{2}}{8(1-\alpha)},
$$


Proof of Proposition 3. Taking Equations (17)-(21), with respect to finding the first-order derivative, we can obtain:

$$
\begin{gathered}
\frac{d e^{D E *}}{d \alpha}=\frac{8(\delta+\eta-\delta k \lambda-c \delta-c \eta-\delta k-\eta k) \theta}{\left((1-\alpha) \theta-(\eta+\delta)^{2}-\lambda \delta^{2}\right)^{2}}>0, \\
\frac{d w^{D E *}}{d \alpha}=\frac{4 \theta(\eta-\delta)(\eta+\delta-\lambda \delta k-c \delta-c \eta-\delta k-\eta k)}{\left(8(1-\alpha) \theta-(\eta+\delta)^{2}-\lambda \delta^{2}\right)^{2}}, \\
\frac{d \mu^{D E *}}{d \alpha}=-\frac{4 \delta \theta(\eta+\delta-\lambda \delta k-c \delta-c \eta-\delta k-\eta k)}{\left(8(1-\alpha) \theta-(\eta+\delta)^{2}-\lambda \delta^{2}\right)^{2}}<0, \\
\frac{d p^{D E *}}{d \alpha}=\frac{2 \theta(3 \eta-\delta)(\eta+\delta-\lambda \delta k-c \delta-c \eta-\delta k-\eta k)}{\left(8(1-\alpha) \theta-(\eta+\delta)^{2}-\lambda \delta^{2}\right)^{2}}, \\
\frac{d \tau^{D E *}}{d \alpha}=-\frac{2 \delta \theta(\eta+\delta-\lambda \delta k-c \delta-c \eta-\delta k-\eta k)}{\left(8(1-\alpha) \theta-(\eta+\delta)^{2}-\lambda \delta^{2}\right)^{2}}<0 .
\end{gathered}
$$

Then, the proof is obtained from the above.

Proof of Proposition 4. Taking Equations (22)-(24), with respect to $\alpha$ finding the first-order derivative, we can obtain:

$$
\begin{gathered}
\frac{d \pi_{m}^{D E *}}{d \alpha}=\frac{((1-c-k)(\eta+\delta)-\lambda \delta k)^{2} \theta}{\left(8(1-\alpha) \theta-(\eta+\delta)^{2}-\lambda \delta^{2}\right)^{2}}>0, \\
\frac{d \pi_{r}^{D E *}}{d \alpha}=\frac{(\eta+\delta) A_{1}(8(1-\alpha)(1-c-k) \theta-\lambda \delta(\delta-c \delta+k \eta)) \theta}{\left(8(1-\alpha) \theta-(\eta+\delta)^{2}-\lambda \delta^{2}\right)^{3}}>0, \\
\frac{d \pi_{t}^{D E *}}{d \alpha}=-\frac{A_{1}(8(1-\alpha) k \theta-(\eta+\delta)(\delta-c \delta+k \eta)) \lambda \delta \theta}{\left(8(1-\alpha) \theta-(\eta+\delta)^{2}-\lambda \delta^{2}\right)^{3}}<0 .
\end{gathered}
$$

where $A_{1}=(\eta+\delta)(1-c-k)-\lambda \delta k$. Then, the proof is obtained from the above.

Proof of Lemma 3. As certified above, it is easy to judge that the retailer profit function regarding the product price and the third-party recycler profit function regarding the recycling price are both one-dimensional concave functions. Then the respective response functions can be obtained from the first-order conditions, as follows:

$$
\begin{gathered}
p^{D S}=\frac{1+w+e \eta-s}{2} \\
\tau^{D S}=\frac{\mu}{2}
\end{gathered}
$$

Substituting the above two equations into the manufacturer's profit function of Equation (25), we can obtain the manufacturer's profit function with respect to the wholesale price and the recovery transfer price as a binary concave function, and the respective reaction functions can be obtained from the first-order conditions as follows:

$$
\begin{gathered}
w^{D S}=\frac{1+k+c+s+\eta e-\delta e}{2}, \\
\mu^{D S}=\frac{k-\delta e}{2} .
\end{gathered}
$$


Substituting Equations (A25) and (A26) above into Equation (25) further yields the manufacturer's profit maximization condition, with respect to the level of ecodesign, as:

$$
\theta>\theta^{D S}=\frac{(\eta+\delta)^{2}+\lambda \delta^{2}}{8}=\theta^{D N} .
$$

Proof of Proposition 5. Taking Equations (29)-(33), with respect to $s$ finding the first-order derivative, we can obtain:

$$
\begin{gathered}
\frac{d e^{D S *}}{d s}=\frac{\eta+\delta}{8 \theta-(\eta+\delta)^{2}-\lambda \delta^{2}}>0, \\
\frac{d w^{D S *}}{d s}=\frac{8 \theta-\lambda \delta^{2}-2 \delta^{2}-2 \delta \eta}{2\left(8 \theta-(\eta+\delta)^{2}-\lambda \delta^{2}\right)}>0 . \\
\frac{d \mu^{D S *}}{d s}=-\frac{\delta(\eta+\delta)}{2\left(8 \theta-(\eta+\delta)^{2}-\lambda \delta^{2}\right)}<0 \\
\frac{d p^{D S *}}{d s}=-\frac{8 \theta-\lambda \delta^{2}-4 \delta \eta-4 \eta^{2}}{4\left(8 \theta-(\eta+\delta)^{2}-\lambda \delta^{2}\right)}<0 \\
\frac{d \tau^{D S *}}{d s}=-\frac{\delta(\eta+\delta)}{4\left(8 \theta-(\eta+\delta)^{2}-\lambda \delta^{2}\right)}<0
\end{gathered}
$$

Then, the proof is obtained from the above.

Proof of Proposition 6. Taking Equations (34)-(36), with respect to $s$ finding the first-order derivative, we can obtain:

$$
\begin{gathered}
\frac{d \pi_{m}^{D S *}}{d s}=\frac{16(1-c-k+s) \theta-2 \lambda \delta(\delta-c \delta+k \eta+\delta s)}{8\left(8 \theta-(\eta+\delta)^{2}-\lambda \delta^{2}\right)}>0, \\
\frac{d \pi_{r}^{D S *}}{d s}=\frac{\left(8 \theta-\lambda \delta^{2}\right)(8(1-c-k+s) \theta-\lambda \delta(\delta-c \delta+k \eta+\delta s)}{8\left(8 \theta-(\eta+\delta)^{2}-\lambda \delta^{2}\right)^{2}}>0 \\
\frac{d \pi_{t}^{D S *}}{d s}=-\frac{\lambda \delta(\eta+\delta)(8 k \theta-(\eta+\delta)(\delta-c \delta+k \eta+\delta s))}{8\left(8 \theta-(\eta+\delta)^{2}-\lambda \delta^{2}\right)^{2}}<0
\end{gathered}
$$

Then, the proof is obtained from the above.

Proof of Lemma 4. As certified above, it is easy to judge that the profit function of the retailer regarding the product price and the profit function of the third-party recycler regarding the recycling price are both one-dimensional concave functions, then the respective response functions can be obtained from the first-order conditions as follows:

$$
\begin{gathered}
p^{D B}=\frac{1+w+b+\eta e}{2}, \\
\tau^{D B}=\frac{\mu}{2}
\end{gathered}
$$

Substituting the above two equations into the manufacturer's profit function of Equation (37), it is easy to judge that the manufacturer's profit function is a binary concave 
function with respect to the wholesale price and the recovery transfer price. Then, the respective reaction functions can be obtained from the first-order conditions as follows:

$$
\begin{gathered}
w^{D B}=\frac{1+k+c+b+\eta e-\delta e}{2}, \\
\mu^{D B}=\frac{k-\delta e}{2}
\end{gathered}
$$

Substituting Equations (A38) and (A39) above into Equation (37) further yields the manufacturer's profit maximization condition with respect to the level of ecodesign as:

$$
\theta>\theta^{D B}=\frac{(\eta+\delta)^{2}+\lambda \delta^{2}}{8}=\theta^{D N}=\theta^{D S},
$$

Proof of Proposition 7. Taking Equations (41)-(45), with respect to $b$ finding the first-order derivative, we can obtain:

$$
\begin{gathered}
\frac{d e^{D B *}}{d b}=\frac{\eta+\delta}{8 \theta-(\eta+\delta)^{2}-\lambda \delta^{2}}>0 \\
\frac{d w^{D B *}}{d b}=\frac{8 \theta-\lambda \delta^{2}-2 \delta^{2}-2 \delta \eta}{2\left(8 \theta-(\eta+\delta)^{2}-\lambda \delta^{2}\right)}>0, \\
\frac{d \mu^{D B *}}{d b}=-\frac{\delta(\eta+\delta)}{2\left(8 \theta-(\eta+\delta)^{2}-\lambda \delta^{2}\right)}<0, \\
\frac{d p^{D B *}}{d b}=\frac{24 \theta-3 \lambda \delta^{2}-4 \delta^{2}-4 \delta \eta}{4\left(8 \theta-(\eta+\delta)^{2}-\lambda \delta^{2}\right)}>0 \\
\frac{d \tau^{D B *}}{d b}=-\frac{\delta(\eta+\delta)}{4\left(8 \theta-(\eta+\delta)^{2}-\lambda \delta^{2}\right)}<0 .
\end{gathered}
$$

Then, the proof is obtained from the above.

Proof of Proposition 8. Taking Equations (46)-(48), with respect to $b$ finding the first-order derivative, we can obtain:

$$
\begin{gathered}
\frac{d \pi_{m}^{D B *}}{d b}=\frac{16(1-c-k+b) \theta-2 \lambda \delta(\delta-c \delta+k \eta+\delta b)}{4\left(8 \theta-(\eta+\delta)^{2}-\lambda \delta^{2}\right)}>0 \\
\frac{d \pi_{r}^{D B *}}{d b}=\frac{\left(8 \theta-\lambda \delta^{2}\right)(8(1-c-k+b) \theta-\lambda \delta(\delta-c \delta+k \eta+\delta b)}{8\left(8 \theta-(\eta+\delta)^{2}-\lambda \delta^{2}\right)^{2}}>0, \\
\frac{d \pi_{t}^{D B *}}{d b}=-\frac{\lambda \delta(\eta+\delta)(8 k \theta-(\eta+\delta)(\delta-c \delta+k \eta+\delta b))}{8\left(8 \theta-(\eta+\delta)^{2}-\lambda \delta^{2}\right)^{2}}<0 .
\end{gathered}
$$

Then, the proof is obtained from the above.

Proof of Lemma 5. As certified above, it is easy to judge that the profit function of the retailer regarding the product price and the profit function of the third-party recycler regarding the recycling price are both one-dimensional concave functions. Then, the respective response functions can be obtained from the first-order conditions as follows:

$$
p^{D F}=\frac{1+w+\eta e}{2},
$$




$$
\tau^{D F}=\frac{\mu+f}{2} .
$$

Substituting the above two equations into the manufacturer's profit function of Equation (49), it is easy to judge that the manufacturer's profit function is a binary concave function with respect to the wholesale price and the recovery transfer price, and then the respective reaction functions can be obtained from the first-order conditions as follows:

$$
\begin{gathered}
w^{D F}=\frac{1+k+c+\eta e-\delta e}{2}, \\
\mu^{D F}=\frac{k-f-\delta e}{2} .
\end{gathered}
$$

Substituting Equations (A51) and (A52) above into Equation (49) further yields the manufacturer's profit maximization condition with respect to the level of ecodesign as:

$$
\theta>\theta^{D F}=\frac{(\eta+\delta)^{2}+\lambda \delta^{2}}{8}=\theta^{D N} .
$$

Proof of Proposition 9. Taking Equations (53)-(57), with respect to $f$ finding the first-order derivative, we can obtain:

$$
\begin{gathered}
\frac{d e^{D F *}}{d f}=-\frac{\lambda \delta}{8 \theta-(\eta+\delta)^{2}-\lambda \delta^{2}}<0, \\
\frac{d w^{D F *}}{d f}=\frac{\lambda \delta(\delta-\eta)}{2\left(8 \theta-(\eta+\delta)^{2}-\lambda \delta^{2}\right)}, \\
\frac{d \mu^{D F *}}{d f}=-\frac{8 \theta-2 \lambda \delta^{2}-\delta^{2}-2 \eta \delta-\eta^{2}}{2\left(8 \theta-(\eta+\delta)^{2}-\lambda \delta^{2}\right)}<0, \\
\frac{d p^{D F *}}{d f}=\frac{\lambda \delta(\delta-3 \eta)}{4\left(8 \theta-(\eta+\delta)^{2}-\lambda \delta^{2}\right)} \\
\frac{d \tau^{D F *}}{d f}=\frac{8 \theta-(\eta+\delta)^{2}}{4\left(8 \theta-(\eta+\delta)^{2}-\lambda \delta^{2}\right)}>0 .
\end{gathered}
$$

Then, the proof is obtained from the above.

Proof of Proposition 10. Taking Equations (58)-(60), with respect to $f$ finding the first-order derivative, we can obtain:

$$
\begin{gathered}
\frac{d \pi_{m}^{D F *}}{d f}=\frac{16 \lambda(k+f) \theta-2 \lambda(\eta+\delta)(\delta-c \delta+k \eta+\delta f+\eta f)}{8\left(8 \theta-(\eta+\delta)^{2}-\lambda \delta^{2}\right)}>0, \\
\frac{d \pi_{r}^{D F *}}{d f}=-\frac{\lambda \delta(\eta+\delta)(8(1-c-k) \theta-\lambda \delta(\delta-c \delta+k \eta+\delta f+\eta f))}{8\left(8 \theta-(\eta+\delta)^{2}-\lambda \delta^{2}\right)^{2}}<0, \\
\frac{d \pi_{t}^{D F *}}{d f}=\frac{\lambda\left(8 \theta-(\eta+\delta)^{2}\right)(8(k+f) \theta-(\eta+\delta)(\delta-c \delta+k \eta+\delta f+\eta f))}{8\left(8 \theta-(\eta+\delta)^{2}-\lambda \delta^{2}\right)^{2}}>0 .
\end{gathered}
$$

Then, the proof is obtained from the above. 


\section{References}

1. Pazoki, M.; Samarghandi, H. Take-back regulation: Remanufacturing or eco-design. Int. J. Prod. Econ. 2020, $227,107674$. [CrossRef]

2. Chekima, B.; Wafa, S.A.W.S.K.; Igau, O.A. Examining green consumerism motivational drivers: Does premium price and demographics matter to green purchasing? J. Clean. Prod. 2016, 112, 3436-3450. [CrossRef]

3. Amacher, G.S.; Koskela, E.; Ollikainen, M. Environmental quality competition and Eco-labeling. J. Environ. Econ. Manag. 2004, 47, 284-306. [CrossRef]

4. Peattie, K. Towards sustainability: The third age of green marketing. Mark. Rev. 2001, 2, 129-146. [CrossRef]

5. Li, Y.; Klaas, V.V. Green, greener, greenest: Eco-label gradation and competition. J. Environ. Econ. Manag. 2015, 72, 164-176. [CrossRef]

6. Bleda, M.; Valente, M. Graded Eco-labels: A demand-oriented approach to reduce pollution. Technol. Forecast Soc. Chang. 2009, 76, 512-524. [CrossRef]

7. Cherian, J.; Jacob, J. Green Marketing: A Study of Consumers' Attitude towards Environment Friendly Products. Asian Soc. Sci. 2012, 8, 117. [CrossRef]

8. Zhang, M.; Feng, G.; Yin, W.; Xie, B.; Ren, M.; Xu, Z. Airborne PCDD/Fs in two e-waste recycling regions after stricter environmental regulations. J. Environ. Sci. 2017, 62, 3-10. [CrossRef]

9. Dias, P.; Machado, A.; Huda, N.; Bernardes, A.M. Waste electric and electronic equipment (WEEE) management: A study on the Brazilian recycling routes. J. Clean. Prod. 2018, 174, 7-16. [CrossRef]

10. Gopalakrishna, K.G.; Reddy, N. Regulations on Recycling PET Bottles. In Recycling of Polyethylene Terephthalate Bottles; William Andrew Publishing: Norwich, UK, 2019; pp. 23-35.

11. Khetriwal, D.S.; Kraeuchi, P.; Widmer, R. Producer responsibility for e-waste management: Key issues for consideration-Learning from the Swiss experience. J. Environ. Manag. 2009, 90, 153-165. [CrossRef]

12. Kiddee, P.; Naidu, R.; Ming, H.W. Electronic waste management approaches: An overview. Waste Manag. 2013, 33, 1237-1250. [CrossRef]

13. Manomaivibool, P. Extended producer responsibility in a non-OECD context: The management of waste electrical and electronic equipment in India. Resour. Conserv. Recycl. 2009, 53, 136-144. [CrossRef]

14. Xia, Y.; Chang, X. Pricing Analysis for Remanufacture Products with Government's Incentive. In Proceedings of the 2010 International Conference on Management and Service Science, Wuhan, China, 24-26 August 2010; pp. 1-5.

15. Tang, Y.; Zhang, Q.; Li, Y. Recycling mechanisms and policy suggestions for spent electric vehicles' power battery-A case of Beijing. J. Clean. Prod. 2018, 186, 388-406. [CrossRef]

16. Nnorom, I.C.; Osibanjo, O. Overview of electronic waste (e-waste) management practices and legislations, and their poor applications in the developing countries. Resour. Conserv. Recycl. 2008, 52, 843-858. [CrossRef]

17. Rahman, S.; Subramanian, N. Factors for implementing end-of-life computer recycling operations in reverse supply chains. Int. J. Prod. Econ. 2012, 140, 239-248. [CrossRef]

18. Zhang, S.; Ding, Y.; Liu, B.; Pan, D.A.; Chang, C.C.; Volinsky, A.A. Challenges in legislation, recycling system and technical system of waste electrical and electronic equipment in China. Waste Manag. 2015, 45, 361-373. [CrossRef]

19. Ding, J.; Chen, W.; Wang, W. Production and carbon emission reduction decisions for remanufacturing firms under carbon tax and take-back legislation. Comput. Ind. Eng. 2020, 143, 106419. [CrossRef]

20. Chen, X.T.; Li, B.Y.; Li, Z.H.; Mark, M.; Wei, S.T. Take-back regulation policy on closed loop supply chains: Single or double targets? J. Clean. Prod. 2021, 283, 124576.

21. OECD. Extended Producer Responsibility: A Guidance Manual for Governments; OECD: Paris, France, 2001.

22. Widmer, R.; Oswald-Krapf, H.; Sinha-Khetriwal, D.; Schnellmann, M.; Böni, H. Global perspectives on e-waste. Environ. Impact. Assess. Rev. 2005, 25, 436-458. [CrossRef]

23. Gupt, Y.; Sahay, S. Review of extended producer responsibility: A case study approach. Waste. Manag. Res. 2015, 33, 595-611. [CrossRef] [PubMed]

24. Arya, S.; Kumar, S. E-waste in India at a glance: Current trends, regulations, challenges and management strategies. J. Clean. Prod. 2020, 271, 122707. [CrossRef]

25. Yu, J.; Hills, P.; Welford, R. Extended producer responsibility and eco-design changes: Perspectives from China. Corp. Soc. Resp. Env. Manag. 2008, 15, 111-124. [CrossRef]

26. Pouikli, K. Concretising the role of extended producer responsibility in European Union waste law and policy through the lens of the circular economy. In ERA Forum; Springer: Berlin/Heidelberg, Germany, 2020; Volume 20, pp. 491-508.

27. Leclerc, S.H.; Badami, M.G. Extended producer responsibility for E-waste management: Policy drivers and challenges. J. Clean. Prod. 2020, 251, 119657. [CrossRef]

28. Pazoki, M.; Zaccour, G. Extended producer responsibility: Regulation design and responsibility sharing policies for a supply chain. J. Clean. Prod. 2019, 236, 117516. [CrossRef]

29. Pazoki, M.; Zaccour, G. A mechanism to promote product recovery and environmental performance. Eur. J. Oper. Res. 2019, 274, 601-614. [CrossRef]

30. Jaunich, M.K.; Decarolis, J.; Handfield, R.; Kemahlioglu-Ziya, E.; Moheb-Alizadeh, H. Life-cycle modeling framework for electronic waste recovery and recycling processes. Resour. Conserv. Recycl. 2020, 161, 104841. [CrossRef] 
31. Daryanto, Y.; Wee, H.M.; Astanti, R.D. Three-echelon supply chain model considering carbon emission and item deterioration. Transport. Res. E Log. 2019, 122, 368-383. [CrossRef]

32. Liu, Z.; Lang, L.; Hu, B.; Shi, L.; Huang, B.; Zhao, Y. Emission reduction decision of agricultural supply chain considering carbon tax and investment cooperation. J. Clean. Prod. 2021, 294, 126305. [CrossRef]

33. Xu, X.; He, P.; Xu, H.; Zhang, Q. Supply chain coordination with green technology under cap-and-trade regulation. Int. J. Prod. Econ. 2017, 183, 433-442. [CrossRef]

34. Ji, J.; Zhang, Z.; Yang, L. Comparisons of initial carbon allowance allocation rules in an O2O retail supply chain with the cap-and-trade regulation. Int. J. Prod. Econ. 2017, 187, 68-84. [CrossRef]

35. Yang, L.; Hu, Y.; Huang, L. Collecting mode selection in a remanufacturing supply chain under cap-and-trade regulation Eur. J. Oper. Res. 2020, 287, 480-496. [CrossRef]

36. Liu, Y.; Quan, B.T.; Xu, Q.; Forrest, J.Y.L. Corporate social responsibility and decision analysis in a supply chain through government subsidy. J. Clean. Prod. 2019, 208, 436-447. [CrossRef]

37. He, P.; He, Y.; Xu, H. Channel structure and pricing in a dual-channel closed-loop supply chain with government subsidy. Int. J. Prod. Econ. 2019, 213, 108-123. [CrossRef]

38. Wang, W.; Ding, J.; Sun, H. Reward-penalty mechanism for a two-period closed-loop supply chain. J. Clean. Prod. 2018, 203, 898-917. [CrossRef]

39. Chen, C.K.; Akmalul'Ulya, M. Analyses of the reward-penalty mechanism in green closed-loop supply chains with product remanufacturing. Int. J. Prod. Econ. 2019, 210, 211-223. [CrossRef]

40. Zhao, Y.; Wang, W.; Ni, Y. EPR system based on a reward and punishment mechanism: Producer-led product recycling channels Waste Manag. 2020, 103, 198-207. [CrossRef] [PubMed]

41. Wang, Y.; Yu, Z.; Shen, L.; Dong, W. Impacts of altruistic preference and reward-penalty mechanism on decisions of E-commerce closed-loop supply chain. J. Clean. Prod. 2021, 315, 128132. [CrossRef]

42. Kraft, T.; Raz, G. Collaborate or compete: Examining manufacturers' replacement strategies for a substance of concern Prod. Oper. Manag. 2017, 26, 1646-1662. [CrossRef]

43. Raz, G.; Druehl, C.T.; Blass, V. Design for the environment: Life-cycle approach using a newsvendor model. Prod. Oper. Manag. 2013, 22, 940-957. [CrossRef]

44. Zheng, X.; Govindan, K.; Deng, Q.; Feng, L. Effects of design for the environment on firms' production and remanufacturing strategies. Int. J. Prod. Econ. 2019, 213, 217-228. [CrossRef]

45. Huang, X.; Atasu, A.; Toktay, L.B. Design implications of extended producer responsibility for durable products. Manag. Sci. 2019, 65, 2573-2590. [CrossRef]

46. Hideki, K. A systematic approach to eco-innovative product design based on life cycle planning. Adv. Eng. Inform. 2006, 20, 113-126.

47. Segonds, F.; Mantelet, F.; Maranzana, N.; Gaillard, S. Early stages of apparel design: How to define collaborative needs for PLM and fashion? Int. J. Technol. Des. Educ. 2014, 7, 105-114. [CrossRef]

48. Harivardhini, S.; Chakrabarti, A. A new model for estimating End-of-Life disassembly effort during early stages of product design. Clean. Technol. Environ. 2016, 18, 1585-1598. [CrossRef]

49. Zeng, T.; Durif, F.; Robinot, E. Can Eco-design packaging reduce consumer food waste? an experimental study. Technol. Forecast Soc. Chang. 2021, 162, 120342. [CrossRef]

50. Gao, J.; Xiao, Z.; Wei, H. Dual-channel green supply chain management with Eco-label policy: A perspective of two types of green products. Comput. Ind. Eng. 2020, 146, 106613. [CrossRef]

51. Nadar, E.; Ertürk, M.S. Eco-design of Eco-labels with coarse grades. Omega 2021, 99, 102209. [CrossRef]

52. Jin, J.; Zhao, Q. Eco-labelled product consumption analysis and incentive-penalty mechanism design by using a system dynamics approach. Comput. Ind. Eng. 2021, 153, 107055. [CrossRef]

53. Sy, M.; Mascle, C. Product design analysis based on life cycle features. J. Eng. Des. 2011, 22, 387-406. [CrossRef]

54. Kralisch, D.; Ott, D.; Gericke, D. Rules and benefits of life cycle assessment in green chemical process and synthesis design: A tutorial review. Green. Chem. 2015, 17, 123-145. [CrossRef]

55. Sanyé-Mengual, E.; Pérez-López, P.; González-García, S.; Lozano, R.G.; Feijoo, G.; Moreira, M.T.; Rieradevall, J. Eco-designing the use phase of products in sustainable manufacturing: The importance of maintenance and communication-to-user strategies. J. Ind. Ecol. 2014, 18, 545-557. [CrossRef]

56. Mendoza, J.M.F.; Sharmina, M.; Gallego-Schmid, A.; Heyes, G.; Azapagic, A. Integrating backcasting and eco-design for the circular economy: The BECE framework. J. Ind. Ecol. 2017, 21, 526-544. [CrossRef]

57. Yokokawa, N.; Masuda, Y.; Amasawa, E. Systematic packaging design tools integrating functional and environmental consequences on product life cycle: Case studies on laundry detergent and milk. Packag. Technol. 2020, 33, 445-459. [CrossRef]

58. Belucio, M.; Rodrigues, C.; Antunes, C.H. Eco-efficiency in early design decisions: A multi-methodology approach. J. Clean. Prod. 2021, 283, 124630. [CrossRef]

59. Parolin, G.; Borges, A.T.; Santos, L.C.C. A tool for aircraft Eco-design based on streamlined Life Cycle Assessment and Uncertainty Analysis. Procedia CIRP 2021, 98, 565-570. [CrossRef] 